\title{
Article \\ Breakdown of Self-Incompatibility in Citrus by Temperature Stress, Bud Pollination and Polyploidization
}

\author{
Rafael Montalt ${ }^{1} \mathbb{D}$, Laura Prósper ${ }^{2}$, María Carmen Vives ${ }^{1} \mathbb{D}$, Luis Navarro $^{2} \mathbb{D}$, Patrick Ollitrault $^{3,4}$ (D) $^{\text {and }}$ \\ Pablo Aleza ${ }^{2, *}$
}

Citation: Montalt, R.; Prósper, L.; Vives, M.C.; Navarro, L.; Ollitrault, P.; Aleza, P. Breakdown of Self-Incompatibility in Citrus by Temperature Stress, Bud Pollination and Polyploidization. Agriculture 2022, 12, 273. https://doi.org/ 10.3390 /agriculture12020273

Academic Editor: Jianjun Chen

Received: 12 January 2022

Accepted: 11 February 2022

Published: 15 February 2022

Publisher's Note: MDPI stays neutral with regard to jurisdictional claims in published maps and institutional affiliations.

Copyright: (C) 2022 by the authors. Licensee MDPI, Basel, Switzerland. This article is an open access article distributed under the terms and conditions of the Creative Commons Attribution (CC BY) license (https:// creativecommons.org/licenses/by/ $4.0 /)$.
1 Centro de Protección Vegetal y Biotecnología, Instituto Valenciano de Investigaciones Agrarias (IVIA), Carretera CV-315, km 10.7, Moncada, 46113 Valencia, Spain; montalt_raf@gva.es (R.M.); vives_mac@gva.es (M.C.V.)

2 Centro de Citricultura y Producción Vegetal, Instituto Valenciano de Investigaciones Agrarias (IVIA), Carretera CV-315, km 10.7, Moncada, 46113 Valencia, Spain; prosper_lau@externos.gva.es (L.P.); lnavarro.ivia@gmail.com (L.N.)

3 UMR AGAP, CIRAD, 20230 San Giuliano, France; patrick.ollitrault@cirad.fr

4 UMR AGAP, Institut Agro, CIRAD, INRAE, Université Montpellier, 34060 Montpellier, France

* Correspondence: aleza@ivia.es

\begin{abstract}
Self-incompatibility (SI) is present in around half of all species of flowering plants. SI limits endogamy and contributes to increased genetic diversity. SI is a very important trait in citrus because, when coupled with parthenocarpy, it allows seedless fruit production. Otherwise, SI is an impediment to genetic studies and breeding programs. Temperature stress, bud pollination and polyploidization can induce the breakdown of the SI mechanism in several species. In this work, we investigated how the SI mechanism can be broken down in two self-incompatible diploid citrus genotypes: 'Fortune' mandarin and 'Clemenules' clementine. The influence of temperature stress on the SI mechanism was assessed in self-pollinated flowers of 'Fortune' mandarins subjected to 2 temperature regimes $\left(10^{\circ} \mathrm{C}\right.$ and $\left.30^{\circ} \mathrm{C}\right)$, whereas the bud pollination effect was investigated in the same genotype and in 'Clemenules' clementines cultivated under field conditions. The tetraploid 'Clemenules' clementine cultivated under field conditions was used to study if tetraploidization can bypass the SI reaction. Histological observations of pollen tube growth and seed production in self-pollinated flowers were used to evaluate the breakdown of SI, while the genetic analysis with SSR and SNP markers confirmed that all recovered plants were zygotic and had been originated by selfing. Our results confirm that the SI reaction can be surpassed by temperature stress, bud pollination and tetraploidy. To our knowledge, this is the first report in citrus in which the SI reaction breakdown by these three different strategies is demonstrated by molecular markers.
\end{abstract}

Keywords: mandarin; flower developmental stage; anthesis; self-pollination; pollen tube; tetraploid; SSR and SNP markers; breeding

\section{Introduction}

Self-incompatibility (SI), also called self-sterility, is defined as "the prevention of selffertilization by otherwise normal and viable gametes, due to their genetic similarity" [1] and was described by Darwin in 1876. SI has been studied thoroughly and has been the subject of a number of important reviews [2-7]. The Brassicaceae and Solanaceae families have been important models for elucidating the molecular mechanism of SI [8-10]. In woody crops, SI has been described in most of the species included in the Rosaceae [11-14], Malvaceae [15], Oleaceae [16] and Rutaceae families [17]. SI avoids endogamy by favoring cross-pollination and contributes to increasing genetic diversity. Thus, it is crucial for species' adaptation and evolution [18-21]. SI is widespread in angiosperm species, and it is estimated that $40-60 \%$ of all species of flowering plants present SI [3-5,22-26]. 
Based on floral morphology, SI systems are classified as homomorphic and heteromorphic. In heteromorphic SI systems, incompatible phenotypes correlate with distinct floral morphological differences, most notably long (pin) or short (thrum) styles that are characteristic of distyly. In contrast, homomorphic SI systems show no distinct floral morphologies in association with the incompatible phenotype, and they comprise all gametophytic SI (GSI) systems and all multi-allelic sporophytic SI (SSI) systems [4,22]. In SSI, the pollen-pistil interaction is determined by the diploid genotype of the parent, whereas in GSI, the compatibility pollen phenotype is determined by the haploid pollen [17,27]. In the Solanaceae, Scrophulariaceae and Rosaceae families, GSI is controlled by a single multiallelic locus, named the S-locus, which is considered to contain at least two linked genes: one encodes glycoproteins with ribonuclease (S-RNase) activity in pistils, while the other is an F-box pollen-expressed gene [28]. In citrus, Soost $[29,30]$ suggested a gametophytic system and estimated a codominant SI gene (S). This author put forward the notion that the SI gene consisted of one self-fertility allele (Sf) that resulted in self-compatibility and at least eight $S$ alleles (Sn) that resulted in SI. Since then, many studies have been undertaken on the citrus SI system. Based on the (SC:SI) ratio obtained in offspring from different crosses, Vardi et al. [31] confirmed the gametophytic SI and proposed different alleles in mandarins. Later novel genes associated with self-pollen rejection in citrus have been identified [32]. Recent studies [33,34] indicate that GSI is based on S-RNase, which acts as a pistil S determinant by inhibiting pollen in an S-specific manner. Both studies analyzed the segregation of markers of S-RNase genes in controlled progenies and found segregations in agreement with this system for some. Based on segregation distortion from reciprocal crosses on high-density genetic maps, Ollitrault et al. [27] confirmed the location of the SI locus at the beginning of chromosome 7 of the clementine reference genome.

Seedlessness is one of the most important characteristics for citrus fresh-fruit markets because consumers do not accept seedy fruit. Several mechanisms have been described in citrus that, when coupled with parthenocarpy, produce seedless fruit; these include for example, ovule sterility in flowers with no functional pistils [35], degeneration [36] and chromosome aberrations in the embryo sac [37], stenospermocarpy [38,39], gene-cytoplasmic interaction [40], gamma irradiation [41,42] and triploidy [43-45]. Besides all these mechanisms, SI is also an efficient way to produce seedless genotypes [43,46]. The most important self-incompatible horticultural citrus groups are pummelos (Citrus maxima (Burm.) Merr.), clementines (C. clementina Hort. ex Tan.), some mandarins, and several natural or artificial hybrids $[17,47,48]$. By taking advantage of histological techniques to observe pollen tube growth inside pistils, different authors have demonstrated that the SI reaction takes place between the stigma and the ovary $[47,49]$. For mandarin hybrids, including the 'Fortune' mandarin (C. clementina $\times$ C. tangerina), and the 'Clemenules' clementine, several authors agree that the SI reaction originates in the upper part of the style [46,47,50-52].

Different causes that induce SI breakdown have been described in several species. At the beginning of the last century, the breakdown of SI by bud pollination was indicated in Nicotiana [53]. It was later described in other species like Petunia [54] and Lilium [55] and in different tribes of the Brassicaceae family [56]. Temperature stress can also bypass the SI reaction, which has been described in Lilium [57,58], Trifolium [59] and Arabidopsis [60]. The polyploidy and self-compatibility association was reported many years ago. As early as 1923, Crane reported SI in the diploid Prunus avium, but SC in the tetraploid P. cerasus. Similar behavior has been found between the natural diploid and tetraploid species of Campanula persicifolia, Allium shoenoprasum and Tulipa spp. (reviewed in [61]). However, a strict comparison between a diploid and its autotetraploid was made thanks to the spontaneous chromosome doubling that occurred in the variety 'Fertility' Pyrus communis, and also when artificial tetraploids in other species were produced by colchicine treatments [61].

Previous studies in citrus have demonstrated that temperature affects not only pollen grain germination but also pollen tube growth dynamics and kinetics [62-64]. In selfincompatible genotypes like clementines, pollen tube growth is arrested in the first third of the style at high temperatures $\left(25-30^{\circ} \mathrm{C}\right)$, whereas very few pollen tubes reach ovaries at 
low temperatures $\left(15-20^{\circ} \mathrm{C}\right)$ [63]. Later, Aloisi et al. [65] indicated the effect of different transglutaminase features and the polyamine pattern on the self-incompatible reaction in clementines. Wakana et al. [66] reported the breakdown of the SI reaction into six different self-incompatible genotypes, including one clementine, two pummelos ('Banpeiyu' and 'Hirado Buntan') and three Japanese varieties, 'Hassaku' (C. hassaku Hort. ex Tan.), 'Hyuganatsu' (C. tamurana Hort. ex Tan) and 'Shishiyuzu' (C. pseudogulgul Hort. ex Shirai). In all these genotypes, these authors recovered seeds from self-pollinated flowers in various development stages, and they concluded that: (i) an appropriate flower bud size for selfpollination is about half the length of flower buds before anthesis; (ii) no SI reaction takes place in this flower bud development stage. Then, Distefano et al. [50] reported that the SI reaction is broken down in two self-incompatible genotypes of mandarin when self-pollinated one day before anthesis. However, these authors did not recover seeds.

Most cultivated citrus plants are diploids $(2 n=2 x=18)$, although aneuploids and euploids can be occasionally found in seedlings [67] or by spontaneous mutations [68]. The above-cited authors identified a tetraploid limb mutation from a diploid self-incompatible 'Hyuganatsu' ancestral Japanese variety. In the reciprocal crosses between diploid and tetraploid 'Hyuganatsu' plants, well-developed and imperfectly developed seeds were recovered in $2 \mathrm{x} \times 4 \mathrm{x}$ and $4 \mathrm{x} \times 4 \mathrm{x}$ hybridizations, whereas no seeds were obtained in $4 \mathrm{x} \times 2 \mathrm{x}$ hybridizations. These results suggest the effect of polyploidy breaking down the SI reaction in citrus.

Despite the above-indicated studies and the importance of SI in citrus, no complete work has demonstrated the breakdown of SI by temperature stress, bud pollination and polyploidization by recovering plants and analyzing their genetic origin with molecular markers. The SI reaction breakdown is a key step to obtain new populations from selfing of self-incompatible parents, which will allow more basic knowledge about SI to be acquired and to expand cross possibilities in breeding programs. The aim of this research was to: (i) evaluate the efficiency for breaking down the SI reaction in citrus by three different methods: temperature stress, bud pollination, and tetraploidy; (ii) recover plants from the three different approaches; (iii) analyze the ploidy level by flow cytometry and determine the genetic origin of the recovered plants using simple sequence repeats (SSR) and single nucleotide polymorphism (SNP) molecular markers.

\section{Materials and Methods}

\subsection{Plant Material}

Two self-incompatible and non-apomictic citrus varieties were used to conduct this study: 'Clemenules' Clementine, which is the main mandarin variety cultivated in Spain for its exceptional fruit quality; and 'Fortune' mandarin, which produces fruits with excellent organoleptical qualities and a very late harvesting period. These varieties are grown in plots in the Citrus Germplasm Bank of the Instituto Valenciano de Investigaciones Agrarias (IVIA) in Moncada, Valencia (Spain). They have the following accession numbers: 'Fortune' mandarin (IVIA-080) and 'Clemenules' clementine (IVIA-022). Tetraploid 'Clemenules' clementine was obtained by shoot tip grafting combined with colchicine treatment [69] and was grafted onto 'Carrizo' citrange (C. sinensis (L.) Osbeck x Poncirus trifoliata (L.) Raf.) in the IVIA experimental plot many years ago. Additionally, 2 6-year-old 'Fortune' mandarin plants cultivated in 50-L containers were used and were grown under field conditions until placed in growth chambers to assess the influence of temperature on the SI reaction. These conditions are described in Section 2.3 Experimental procedure, Section 2.3.1, Experiment 1.

\subsection{Pollination Procedure, Sample Storage and Seed Germination}

In order to perform hand pollinations, anthers were removed from the flowers of the donors randomly harvested in the balloon stage and were dried in Petri dishes on silica gel in a desiccator at room temperature until dehiscence (24-48 h). The dehiscent anthers were used for pollination. The hand-pollinated flowers were emasculated and bagged to avoid undesired pollination. Depending on the experiment conditions, the flowers in the 
different developmental stages were pollinated at different times spanning from pollination to sample storage. These differences are detailed below. Flowers were fixed in FAA solution (formalin, glacial acetic acid, 70\% ethanol, 1:1:18, v/v) [70] and stored at $4{ }^{\circ} \mathrm{C}$ pending histological observations. The other flowers were left for fruit set. Fruits were collected when ripe, and the number of seeds per fruit was recorded. Normal developed seeds were germinated under standard greenhouse conditions to produce seedlings for ploidy and genetic analyses.

\subsection{Experimental Procedure}

Three independent self-pollination experiments were carried out under different conditions indicated below as Experiments 1, 2 and 3. Additionally, self- and cross-pollination under field conditions and cross-pollination in the temperature regimes studied in Experiment 1 were performed to confirm the normal behavior of pollen performance in the flowers utilized in our experiments. The average temperature under field conditions within the experimental time frame was $18.5^{\circ} \mathrm{C}$, with a typically gradual increase from less than $10{ }^{\circ} \mathrm{C}$ at night to up to $30^{\circ} \mathrm{C}$ in the daytime. The temperature data was acquired by an automatic weather station located at IVIA (Moncada, Valencia, Spain). To pollinate 'Fortune' mandarin flowers, we used the pollen of the 'Clemenules' clementine and vice versa. We employed these genotypes for their high pollination aptitude and the compatibility between them.

\subsubsection{Experiment 1}

The influence of temperature stress on the SI reaction was assessed in adult trees of the 'Fortune' mandarin cultivated in 50-L containers. Two temperature regimes were used: a low-temperature regime with an average of $10^{\circ} \mathrm{C}$ and a warm temperature regime with an average of $30^{\circ} \mathrm{C}$. For this purpose, during the flowering period, one adult tree was placed in each of the growth chambers for both temperature regimes and was exposed to $80 \mu \mathrm{E} \mathrm{m}^{-2} \mathrm{~s}^{-1}$ illumination for $16 \mathrm{~h}$ daily. In the immediate following days (1 to 2 days at $30{ }^{\circ} \mathrm{C}$ and 1 to 5 days at $10^{\circ} \mathrm{C}$ ), 25 flowers at anthesis for each temperature regime were used to perform hand-pollination; ten flowers were used for histological observations (Supplementary Table S1), and 15 flowers were left for fruit setting. According to our previous results about the influence of temperature on the citrus progamic phase [64], the time between pollination and FAA fixation differed depending on the temperature regime under study. At $10{ }^{\circ} \mathrm{C}$, flowers were fixed 20 days after pollination, whereas at $30{ }^{\circ} \mathrm{C}$, flowers were fixed 4 days after pollination. Once self-pollinated flowers had been collected for histological observations, trees were left under field conditions.

\subsubsection{Experiment 2}

The influence of bud pollination on the SI reaction was assessed in adult 'Fortune' mandarin and 'Clemenules' clementine trees cultivated under field conditions. In each genotype, 40 flower buds of different sizes were selected and measured using a digital caliper. Based on the measured length, flower buds were classified and tagged in four developmental stages (A-D, see Figure 1). The flower bud length used for this experiment spanned from 8.6 to $15.8 \mathrm{~mm}$ in 'Fortune' mandarin (Supplementary Table S2) and from 8.2 to $16.0 \mathrm{~mm}$ in 'Clemenules' clementine (Supplementary Table S3). The tagged flower buds were self-pollinated and bagged to avoid undesired cross-pollination. A total of 5 pollinated pistils that corresponded to each developmental stage were harvested 10 days after pollination, fixed in FAA solution and kept at $4{ }^{\circ} \mathrm{C}$ until histological observations were performed. The remaining five self-pollinated flowers in each developmental stage were left for fruit setting. In order to categorize developmental stages (A-D, see Figure 1), five more flowers at each stage were labeled and monitored until anthesis occurred. The number of days before anthesis was five to seven for stage A; two to four for stage B; and one to two for stage C. D refers to flowers at the balloon stage (flowers very close to anthesis that opened in one or less than one day after labeling). 


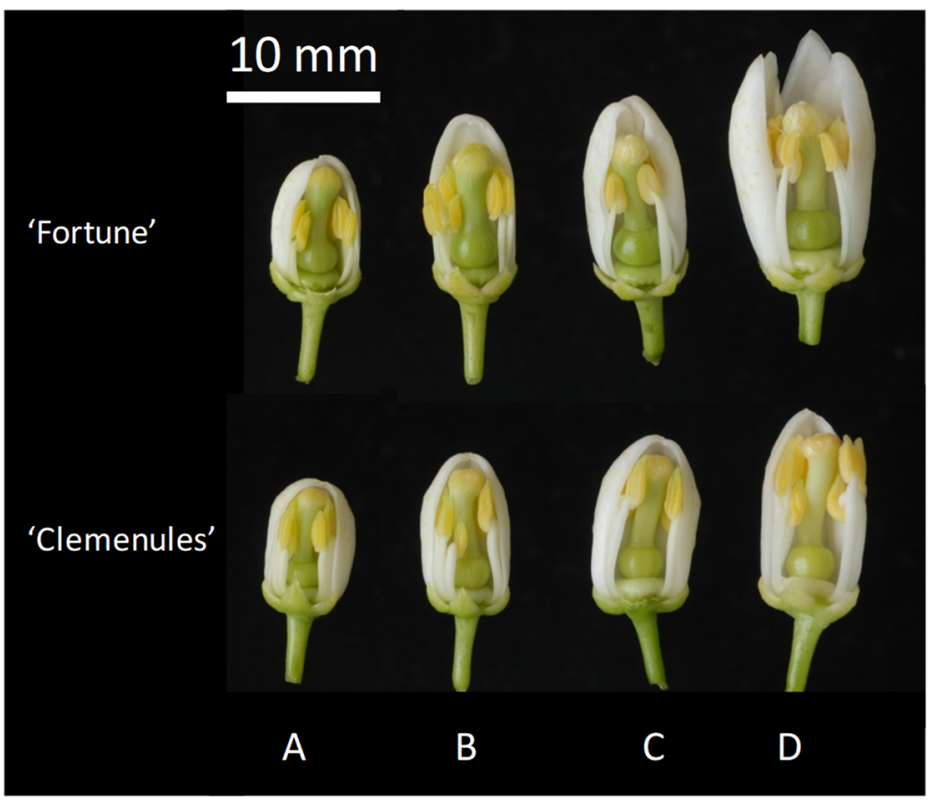

Figure 1. Developmental stages of the self-pollinated flowers used to evaluate SI breakdown by bud pollination in 'Fortune' mandarin and 'Clemenules' clementine.

\subsubsection{Experiment 3}

The influence of polyploidization on the SI reaction was assessed in one adult tree of the tetraploid 'Clemenules' clementine cultivated under field conditions in the IVIA plots. Twenty-five flowers at anthesis were manually self-pollinated and bagged. Eight of them were fixed in FAA ten days after pollination (Supplementary Table S4), and the rest were left until fruit set.

\subsection{Histological Observations}

The pistils fixed in FAA were submerged 3 times in water for $1 \mathrm{~h}$. Then, pistils were sliced into 14 cross-sections using a sharp blade. Stigmas were sliced into two sections, styles into eight sections and ovaries into four sections, following the methodology described by Montalt et al. [64]. Sections were stained with $0.1 \%$ aniline blue in $0.1 \mathrm{~N}$ $\mathrm{K}_{3} \mathrm{PO}_{4}$ [71]. Pollen tube growth was identified by its callose plugs fluorescence [72] and was visualized under a Leica MZ16FA epifluorescence stereomicroscope using a GFP1 excitation filter 395-455 nm and barrier filter $480 \mathrm{LP}$. In each analyzed pistil, pollen tube growth was assessed based on the percentage of the pistil reached by pollen tubes and the number of pollen tubes that had reached the ovary (Supplementary Tables S1-S4). In some samples, the number of pollen tubes reaching the ovaries emitted high fluorescence, which did not allow pollen tubes to be individually counted, and a decision was made to classify them as " $>10$ ". For the easy view and systematic presentation of the results, the number of pollen tubes that reached ovaries appears in brackets; less than five pollen tubes $(<5)$, between five and ten pollen tubes (5-10) and more than ten pollen tubes $(>10)$.

\subsection{Ploidy Level Analysis by Flow Cytometry}

Ploidy level was determined by flow cytometry according to the methodology described by Aleza et al. [69]. Each sample consisted of a small piece of leaf $\left(\sim 0.5 \mathrm{~mm}^{2}\right)$ collected from each plant with a similar leaf piece taken from a diploid control plant. Samples were chopped together using a razor blade in the presence of a nuclei isolation solution (High Resolution DNA Kit Type P, solution A; Partec, Münster, Germany). Nuclei were filtered through a 30- $\mu$ m nylon filter and stained with DAPI (4,6-diamine-2-phenylindol) (High Resolution DNA Kit Type P, solution B; Partec) solution. After a 5-min incubation period, the stained samples were run in a CyFlow Ploidy Analyzer (Partec) flow cytometer 
equipped with optical parameters to detect DAPI fluorescence. DNA fluorochrome DAPI was excited by the UV-LED at $365 \mathrm{~nm}$. Histograms were analyzed with the CyView software (Partec), which determines the peak position, coefficient of variation (CV), arithmetic mean and median of samples.

\subsection{Genetic Analysis with Simple Sequence Repeat (SSR) and Single Nucleotide Polymorphism (SNP) Markers}

The plants recovered from the three independent experiments were genotyped using SSR and SNP markers located along the nine linkage groups of the reference clementine genetic map [73]. In all, four SSR and seven SNP heterozygous markers for 'Fortune' mandarin and three SSR and nine SNP heterozygous markers for 'Clemenules' clementine were selected to analyze the genetic origin of the recovered plants. Detailed information and bibliographic references [74-78] about all the used markers are provided in Supplementary Table S5.

Genomic DNA was extracted from leaves using the Plant DNeasy kit (Quiagen, Hilden, Germany) following the manufacturer's protocol and was measured using a spectrophotometer (NanoDrop 2000C, Thermo Fisher, Waltham, MA, USA). Samples were diluted with sterile water (Sigma-Aldrich, Co. Burlington, MA, USA) at a concentration of $10 \mathrm{ng} / \mu \mathrm{L}$ and stored at $20^{\circ} \mathrm{C}$ until used.

Polymerase chain reactions (PCRs) were performed using the SSR markers with a Mastercycler ep gradient S (Eppendorf@. Hamburg, Germany) according to the following protocol: reaction volume $15 \mu \mathrm{L}$ containing $0.5 \mu \mathrm{L}$ of $1 \mathrm{U} / \mu \mathrm{L}$ of Taq DNA polymerase (Fermentas@. Waltham, MA, USA), $3 \mu \mathrm{L}$ of the citrus template DNA $(10 \mathrm{ng} / \mu \mathrm{L}), 1.5 \mu \mathrm{L}$ of $2 \mu \mathrm{M}$ welled (Sigma@. Burlington, MA, USA) dye-labeled forward primer, $1.5 \mu \mathrm{L}$ of $2 \mu \mathrm{M}$ non-dye-labeled reverse primer, $0.2 \mu \mathrm{M}$ of each dNTP, $1.5 \mu \mathrm{L}$ of PCR reaction buffer $10 \mathrm{X}$ and $0.45 \mu \mathrm{L}$ of $50 \mathrm{mM} \mathrm{MgCl}_{2}$. The cycling program was set as follows: denaturation for $5 \mathrm{~min}$ at $94^{\circ} \mathrm{C}$ followed by 40 cycles of $30 \mathrm{~s}$ at $94{ }^{\circ} \mathrm{C}, 30 \mathrm{~s}$ at $50{ }^{\circ} \mathrm{C}$ or $55^{\circ} \mathrm{C}, 30 \mathrm{~s}$ at $72{ }^{\circ} \mathrm{C}$; and a final elongation step of $8 \mathrm{~min}$ at $72{ }^{\circ} \mathrm{C}$. Separation was carried out by capillary gel electrophoresis in a Genetic Analysis System 8000 (Beckman Coulter Inc., Brea, CA, USA). PCR products were initially denatured at $90{ }^{\circ} \mathrm{C}$ for $2 \mathrm{~min}$, injected at $2 \mathrm{kV}$ for $30 \mathrm{~s}$, and separated at $6 \mathrm{kV}$ for $35 \mathrm{~min}$. Alleles were size-based on a DNA size standard (400 bp). The GenomeLab v.10.0 (Beckman Coulter Inc., Brea, CA, USA) genetic analysis software was used for data collection.

The recovered plants were also genotyped with the SNP markers following the KASPar technology (LGC Genomics, Ipswich, UK). The KASPar Genotyping System is a competitive allele-specific dual Förster resonance energy transfer (FRET)-based assay for SNP genotyping. Primers were directly designed by the LGC Genomics Company based on the SNP locus-flanking sequence ( $~ 50$ nt on each side of the SNP). SNP genotyping was performed by the KASPar technique. A detailed description of the specific conditions and reagents can be found in [79].

\subsection{Population Diversity Analysis}

The population diversity organization between the diploid and tetraploid plants recovered from the self-pollination of 'Fortune' mandarin and tetraploid 'Clemenules' clementine, respectively, was examined with the DARwin6 software [80]. A neighborjoining analysis was performed using the simple matching dissimilarity index $\left(d_{i-j}\right)$ between pairs of markers (units):

$$
d_{i-j}=1-\frac{1}{L} \sum_{l=1}^{L} \frac{m_{l}}{\pi}
$$

where $d_{i-j}$ is the dissimilarity between units $i$ and $j, L$ is the number of markers, $m_{l}$ is the number of matching alleles for marker $l$, and $\pi$ is the ploidy level. From the obtained dissimilarity matrix, a weighted neighbor-joining tree [81] was computed. 


\section{Results}

Figure 2 shows examples of the performed control pollinations. As expected: (i) in the self-pollinated flowers of 'Clemenules' clementine and 'Fortune' mandarin under field conditions, no pollen tubes reached the ovaries in any analyzed pistil; (ii) in the cross-pollinations between 'Clemenules' $\times$ 'Fortune' and 'Fortune' $\times$ 'Clemenules' under field conditions, all the analyzed pistils displayed pollen tubes that reached the ovaries with more than 10 pollen tubes in them; (iii) in the cross-pollinations between 'Fortune' $\times$ 'Clemenules' at $10^{\circ} \mathrm{C}$ and $30{ }^{\circ} \mathrm{C}$, all the analyzed pistils displayed pollen tubes that reached the ovaries with more than 10 pollen tubes in them.

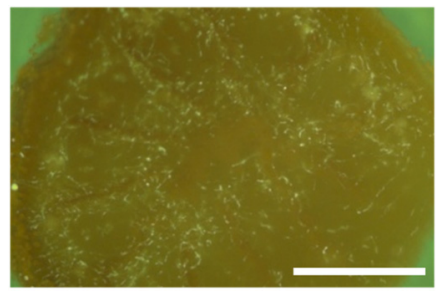

(a)

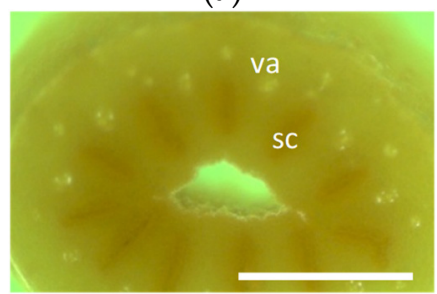

(b)

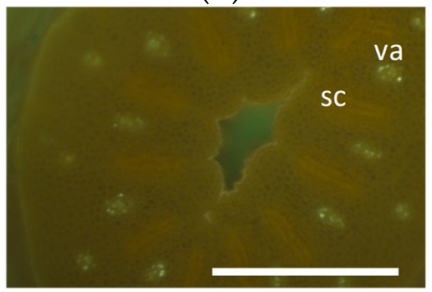

(c)

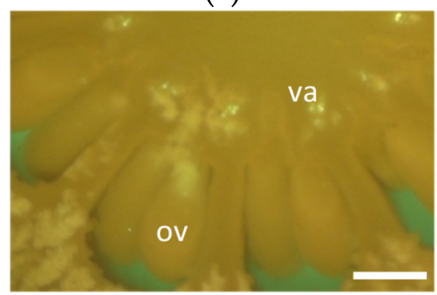

(d)

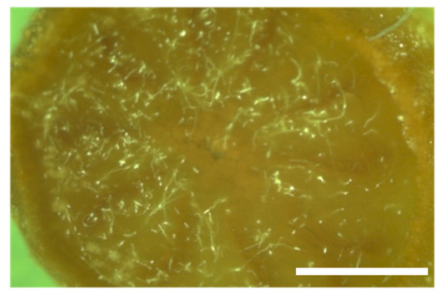

(e)

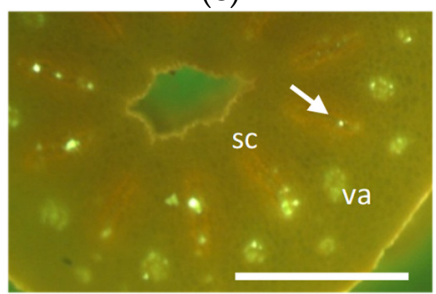

(f)

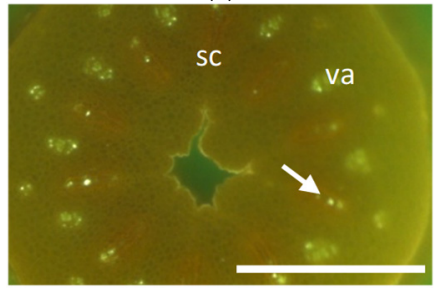

(g)

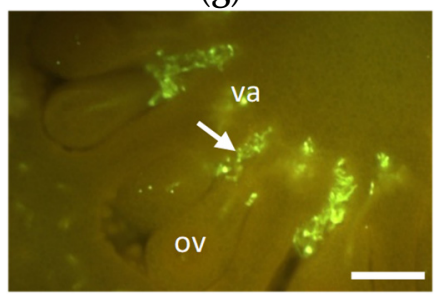

(h)

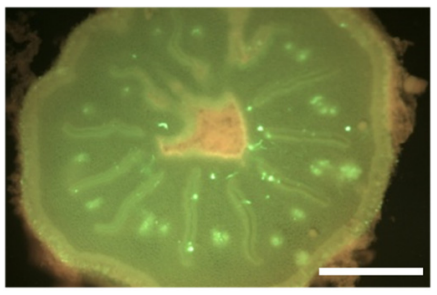

(i)

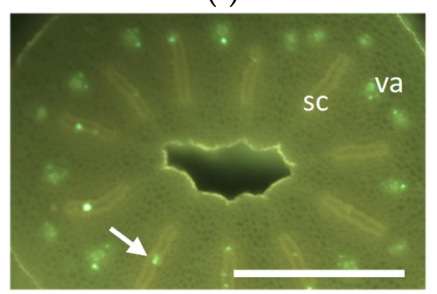

(j)

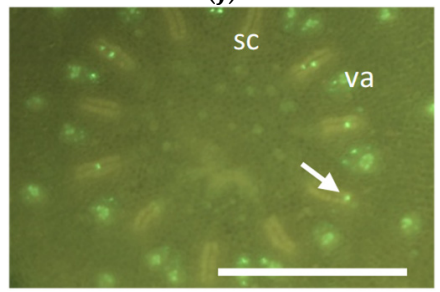

(k)

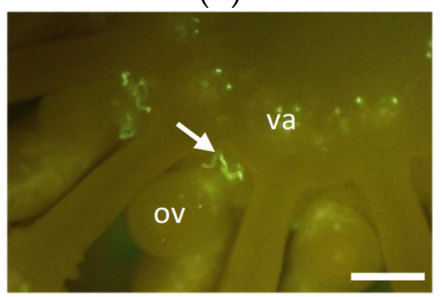

(1)

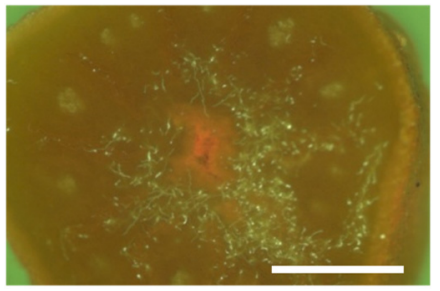

(m)

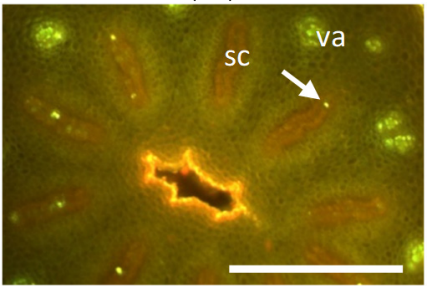

(n)

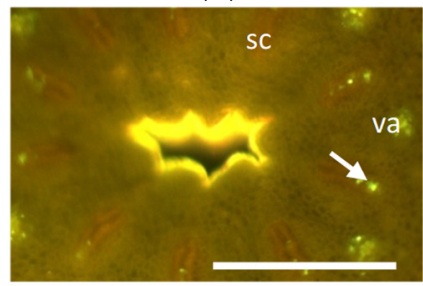

(o)

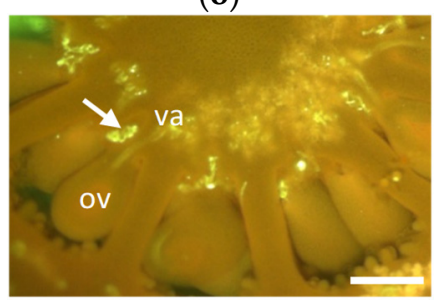

$(\mathbf{p})$

Figure 2. Histological sections of 'Fortune' mandarin pistils. (a-d) Self-pollinated pistils under field conditions. (e-h) Cross-pollinated pistils under field conditions. (i-l) Cross-pollinated pistils at $10^{\circ} \mathrm{C}$. $(\mathbf{m}-\mathbf{p})$ Cross-pollinated pistils at $30^{\circ} \mathrm{C}$. The pollen from 'Clemenules' clementine was used for cross-pollinations. Pollen tubes are marked by an arrow; va: vascular axis; sc: stylar canal; ov: ovule. Scale bars are depicted by white lines: $(\mathbf{a}, \mathbf{e}, \mathbf{i}, \mathbf{m}) 1 \mathrm{~mm} ;(\mathbf{b}, \mathbf{c}, \mathbf{f}, \mathbf{g}, \mathbf{j}, \mathbf{k}, \mathbf{n}, \mathbf{n}, \mathbf{o}) 0.5 \mathrm{~mm} ;(\mathbf{d}, \mathbf{h}, \mathbf{l}, \mathbf{p}) 0.2 \mathrm{~mm}$.

\subsection{SI Breakdown by Temperature Stress (Experiment 1)}

At $10{ }^{\circ} \mathrm{C}$, we noted that fewer than 5 pollen tubes reached the ovaries (Figure $3 c, d$ ) in $80 \%$ of the self-pollinated flowers; fruits harvested from the self-pollinated flowers had an average of 1.4 seeds per fruit (Table 1). By considering both histological observations and seed production from the self-pollinated flowers at $10^{\circ} \mathrm{C}$, we demonstrated that pollen tubes were able to reach the ovaries, fertilize ovules and produce seeds. All this indicates that SI in the self-incompatible genotype 'Fortune' mandarin breaks down at $10{ }^{\circ} \mathrm{C}$. At 
$30{ }^{\circ} \mathrm{C}$, we observed some pollen tubes growing below the upper half of the style in $20 \%$ of the self-pollinated flowers. However, no pollen tubes were observed reaching the ovaries in any of them (Figure 3g,h). Moreover, no fruits were obtained, and consequently, seed presence could not be assessed at $30^{\circ} \mathrm{C}$ (Table 1 ).

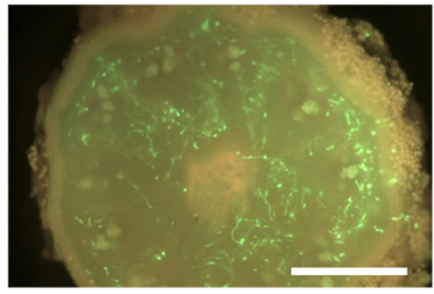

(a)

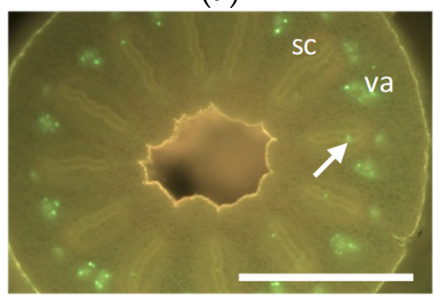

(b)

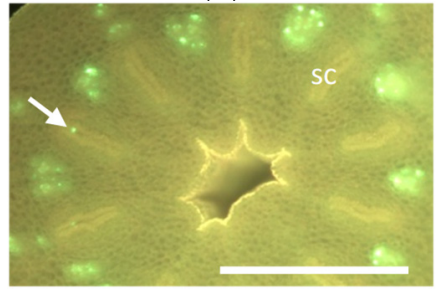

(c)

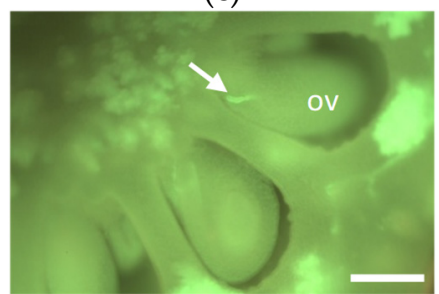

(d)

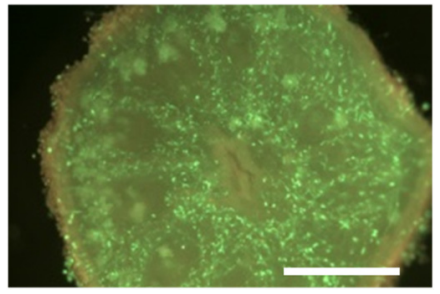

(e)

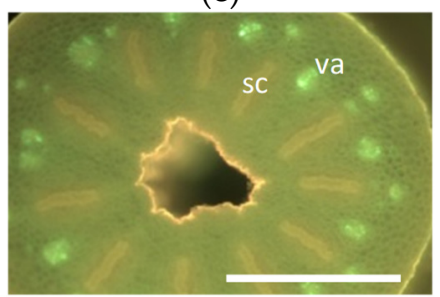

(f)

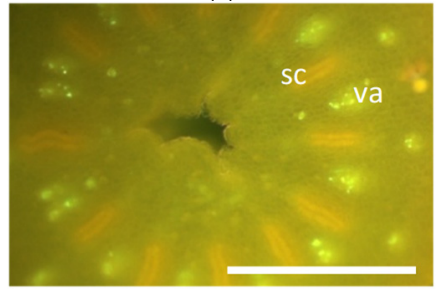

(g)

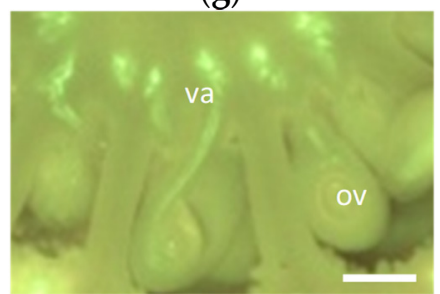

(h)

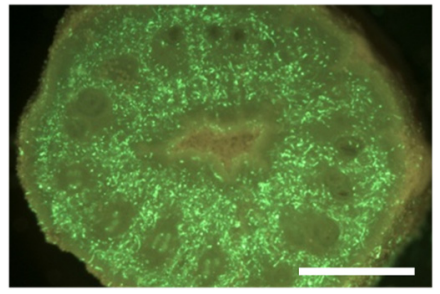

(i)

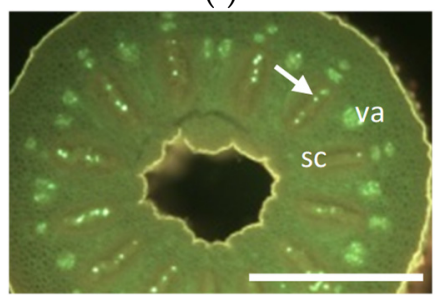

(j)

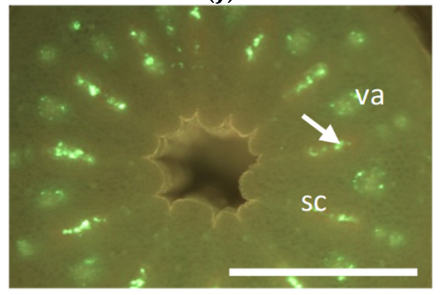

(k)

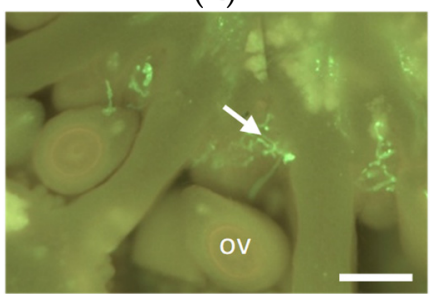

(1)

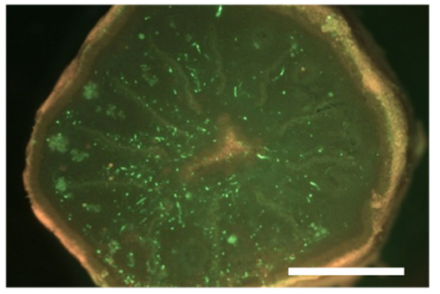

$(\mathbf{m})$

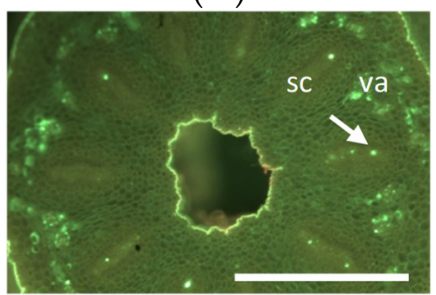

(n)

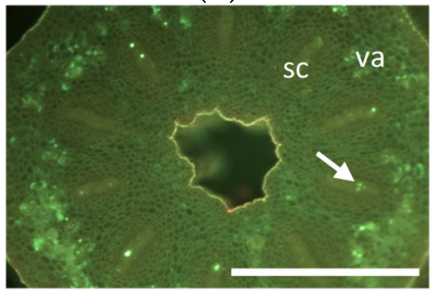

(o)

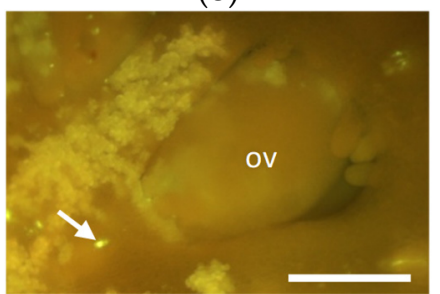

(p)

Figure 3. Histological sections of the self-pollinated pistils analyzed in the three experiments. (a-d) Self-pollinated pistil of 'Fortune' mandarin at $10^{\circ} \mathrm{C}$. (e-h) Self-pollinated pistil of 'Fortune' mandarin at $30^{\circ} \mathbf{C}$. (i-1) Self-pollinated buds of 'Fortune' mandarin. (m-p). Self-pollinated pistil of the tetraploid 'Clemenules' clementine. Pollen tubes are marked by an arrow; va: vascular axis; sc: stylar canal; ov: ovule. Scale bars are depicted by white lines: $(\mathbf{a}, \mathbf{e}, \mathbf{i}, \mathbf{m}) 1 \mathrm{~mm} ;(\mathbf{b}, \mathbf{c}, \mathbf{f}, \mathbf{g}, \mathbf{j}, \mathbf{k}, \mathbf{k}, \mathbf{o})$ $0.5 \mathrm{~mm} ;(\mathbf{d}, \mathbf{h}, \mathbf{l}, \mathbf{p}) 0.2 \mathrm{~mm}$.

\subsection{SI Breakdown by Bud Pollination (Experiment 2)}

Both 'Fortune' mandarin and 'Clemenules' clementine showed similar results. In all the self-pollinated buds with average lengths of $14.7 \mathrm{~mm}$ in 'Fortune' mandarin and of $14.9 \mathrm{~mm}$ in 'Clemenules' clementine (D in Figure 1), no pollen tubes reached the ovaries, and all the obtained fruits were seedless (Table 1). In the self-pollinated buds with an average length of $12.5 \mathrm{~mm}$ in 'Fortune' mandarin and $12.1 \mathrm{~mm}$ in 'Clemenules' clementine (C in Figure 1), 60\% and 40\% of pistils showed fewer than 5 pollen tubes reaching the ovaries in 'Fortune' mandarin and 'Clemenules' clementine, respectively, while no pollen tubes were observed in the rest. However, more than 10 pollen tubes (Figure $3 k, 1)$ were observed in all the ovaries of the self-pollinated buds at early developmental stages with an average length of $9.9 \mathrm{~mm}$ in 'Fortune' mandarin and of $9.4 \mathrm{~mm}$ in 'Clemenules' clementine 
(A and B in Figure 1). All the obtained fruits were seedy and contained an average of 22.3 and 17.5 seeds per fruit in 'Fortune' mandarin and 'Clemenules' clementine, respectively (Table 1). The absence of stigmatic exudation should be noted in stigmas in early developmental stages (A and B in Figure 1) when successful pollen performance occurred. This fact indicates that the presence of stigmatic exudation does not reflect stigmatic receptivity.

Table 1. Pollen tube growth (PTG) and seed production obtained from the self-pollinated flowers in each experiment.

\begin{tabular}{|c|c|c|c|c|c|c|}
\hline Experiment & Genotype & Temp. & Flower Stage & $\begin{array}{c}\text { PTG } \\
(\%)\end{array}$ & $\begin{array}{l}\text { PTG } \\
\text { (No.) }\end{array}$ & $\begin{array}{l}\text { Seed Production } \\
\text { (No. per Fruit) }\end{array}$ \\
\hline Exp. 1 & 'Fortune' & $10^{\circ} \mathrm{C}$ & \multirow[b]{2}{*}{ Anthesis } & 80 & $<5$ & $1.4 \pm 0.8$ \\
\hline Temperature stress & 'Fortune' & $30{ }^{\circ} \mathrm{C}$ & & 0 & 0 & - \\
\hline \multirow{6}{*}{$\begin{array}{l}\text { Exp. } 2 \\
\text { Bud Pollination }\end{array}$} & 'Fortune' & FC & Bud $(14.7 \pm 1.0)(\mathrm{D})$ & 0 & 0 & 0 \\
\hline & 'Fortune' & FC & Bud $(12.5 \pm 0.7)(\mathrm{C})$ & 60 & $<5$ & - \\
\hline & 'Fortune' & FC & $\operatorname{Bud}(9.9 \pm 0.9)(\mathrm{A}-\mathrm{B})$ & 100 & $>10$ & $22.3 \pm 2.5$ \\
\hline & ‘Clemenules' & FC & Bud $(14.9 \pm 0.8)(\mathrm{D})$ & 0 & 0 & 0 \\
\hline & 'Clemenules' & FC & Bud $(12.1 \pm 0.5)(\mathrm{C})$ & 40 & $<5$ & - \\
\hline & 'Clemenules' & $\mathrm{FC}$ & Bud $(9.4 \pm 0.9)(\mathrm{A}-\mathrm{B})$ & 100 & $>10$ & $17.5 \pm 7.7$ \\
\hline $\begin{array}{c}\text { Exp. } 3 \\
\text { Polyploidization }\end{array}$ & 'Clemenules' 4x & FC & Anthesis & 100 & $5-10$ & $5 \pm 1.4$ \\
\hline
\end{tabular}

FC. Field conditions. Flower stage is indicated as 'Anthesis' or 'Bud'. In parenthesis after 'Bud', the following information is included: (1) bud length ( $\mathrm{mm})$ expressed as the mean $\pm \mathrm{SD}(n=5)$; (2) capital letters (A to D) indicating flower developmental stages, as shown in Figure 1. PTG is expressed as the percentage (\%) of pistils in which pollen tubes reached ovaries and as the number (No.) of pollen tubes that reached ovaries. PTG (No.) is given as the maximum interval in Supplementary Tables S1-S4. Seed production (number of seeds per fruit) is expressed as the mean $\pm \mathrm{SD}$ ( $n=5$ to 13 depending on the number of fruit obtained in the treatment).

\subsection{SI Breakdown by Polyploidization (Experiment 3)}

The histological observations (Figure 3o,p) showed that pollen tubes reached the ovaries in all the self-pollinated flowers, and fruits harvested from the self-pollinated flowers had an average of five seeds per fruit (Table 1). By taking into account both histological observations and seed production from the self-pollinated flowers of the tetraploid 'Clemenules' clementine, we conclude that SI breaks down by polyploidization in this genotype.

\subsection{Ploidy Level Analysis by Flow Cytometry}

The number of plants recovered from the germination of the normally developed seeds obtained in each experiment was: (i) 7 plants by self-pollination of the 'Fortune' mandarin at $10^{\circ} \mathrm{C}$ (Experiment 1$) ; 81$ and 61 plants by bud self-pollination of the 'Fortune' mandarin and 'Clemenules' clementine, respectively (Experiment 2); 29 plants by the self-pollination of the tetraploid 'Clemenules' clementine (Experiment 3). The analysis of flow cytometry showed that all the plants recovered from Experiments 1 and 2 were diploids, and all the plants recovered from Experiment 3 were tetraploids. These results agree with the selfing hypothesis.

\subsection{Genetic Analysis with the SSR and SNP Markers}

Genetic analyses of recovered plants were performed to rule out any uncontrolled pollination hypothesis and to evaluate segregation distortion. The plants recovered from the self-pollination of the 'Fortune' mandarin at $10^{\circ} \mathrm{C}$ (Experiment 1) and from the bud self-pollination of the 'Fortune' mandarin (Experiment 2) were analyzed with four SSR markers heterozygous for 'Fortune' mandarin (Supplementary Table S5). The results for the SSR markers showed that all the plants recovered from Experiment 1 (Supplementary Table S6) and from Experiment 2 (Supplementary Table S7) displayed unambiguous 'Fortune' mandarin alleles. 
The plants recovered from the bud self-pollination of the 'Fortune' mandarin (Experiment 2) were also analyzed with seven SNP markers heterozygous for 'Fortune' mandarin (Supplementary Table S5). By way of example, Figure 4a shows the results obtained for the PKF-M186 SNP marker. The analyzed hybrids are clustered in three different groups corresponding to the expected segregation according to the self-pollination hypothesis, with two groups in homozygosity (TT and CC) and one group in heterozygosity (TC), in which the 'Fortune' mandarin is included.

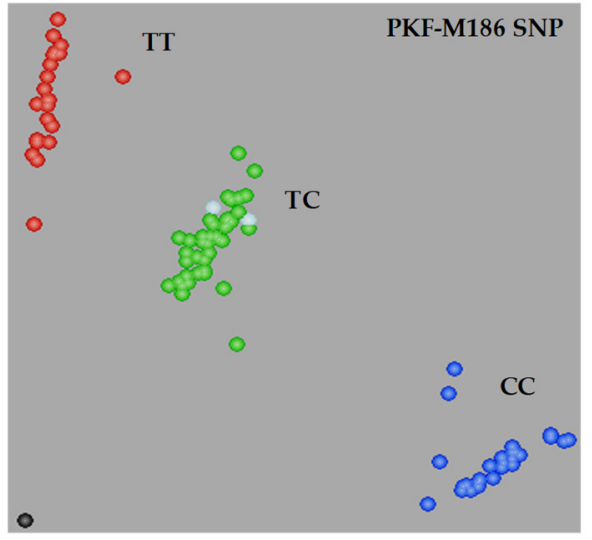

(a)

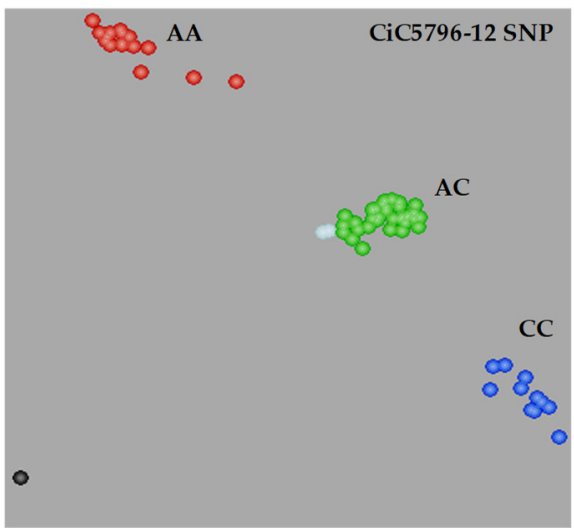

(b)

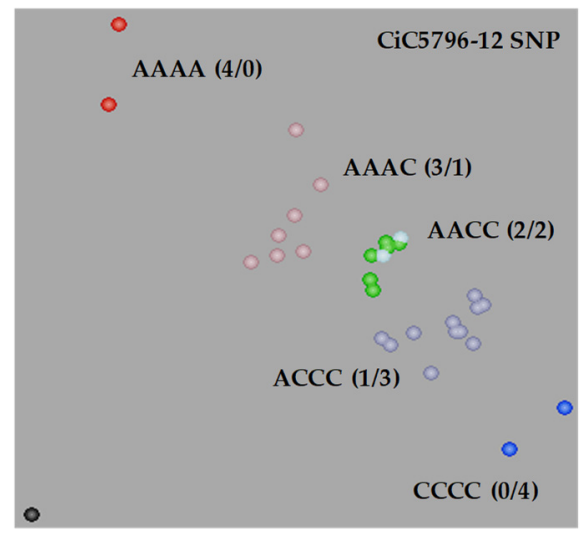

(c)

Figure 4. (a) Plot of the T and C allele signals of the PKF-M186 SNP marker from the cluster analysis of 80 diploid hybrids recovered by the self-pollination of the 'Fortune' mandarin by bud pollination. Diploid homozygous (TT and CC) and heterozygous hybrids (TC) originated from the heterozygous 'Fortune' mandarin indicated by white spots. (b) Plot of the A and C allele signals of the CiC5796-12 SNP marker from the cluster analysis of 61 diploid hybrids recovered by the self-pollination of the diploid 'Clemenules' clementine by bud pollination. Diploid homozygous (AA and $\mathrm{CC}$ ) and heterozygous hybrids (AC) originated from the heterozygous $2 x$ clementine indicated by white spots. (c) Plot of the A and C allele signals of the CiC5796-12 SNP marker from the cluster analysis of $294 \mathrm{x}$ hybrids recovered by the self-pollination of $4 \mathrm{x}$ 'Clemenules' clementine. Tetraploid homozygous (AAAA and CCCC, with $4 / 0$ and $0 / 4$ allele dosage, respectively) and tetraploid heterozygous hybrids (AAAC, AACC and ACCC with 3/1,2/2 and 1/3 allele dosage, respectively) originated from heterozygous $4 \mathrm{x}$ clementine indicated by white spots.

None of the plants recovered by Experiments 1 and 2 were identical to the diploid 'Fortune' mandarin (Figure 5a), as they displayed different allelic configurations (Supplementary Tables S6 and S7). Moreover, all the plants displayed some markers in heterozygosity, which allowed the doubled haploid origin hypothesis to be ruled out.

Potential distortions toward Mendelian allelic segregations were tested in the population obtained from bud pollination for each marker using the Chi-squared test $(0.05$ probability threshold) with Bonferroni correction for multiple testing. Only the NADK2-M285 SNP marker showed a significant segregation distortion $(p$-value $=0.001)($ Table 2$)$. Considering that flowers were bagged after self-pollination, flow cytometry and the observed segregation, we conclude that we obtained diploid zygotic plants that resulted from the self-pollination of 'Fortune' mandarin.

Detailed information on the markers is provided in Supplementary Table S5. The data under aa, AA and Aa columns indicate the number of individuals with that allelic configuration.

The diploid plants recovered from the bud self-pollination of 'Clemenules' clementine (Experiment 2), and the tetraploid plants obtained from the self-pollination of tetraploid 'Clemenules' clementine (Experiment 3) were analyzed with three SSR markers heterozygous for 'Clemenules' clementine (Supplementary Table S5). The results for the SSR markers showed that all the plants recovered from Experiment 2 (Supplementary Table 
S8) and from Experiment 3 (Supplementary Table S9) displayed unambiguous alleles of 'Clemenules' clementine. By considering these results and the fact that flowers were bagged after self-pollination, we discarded any undesired cross-pollination.

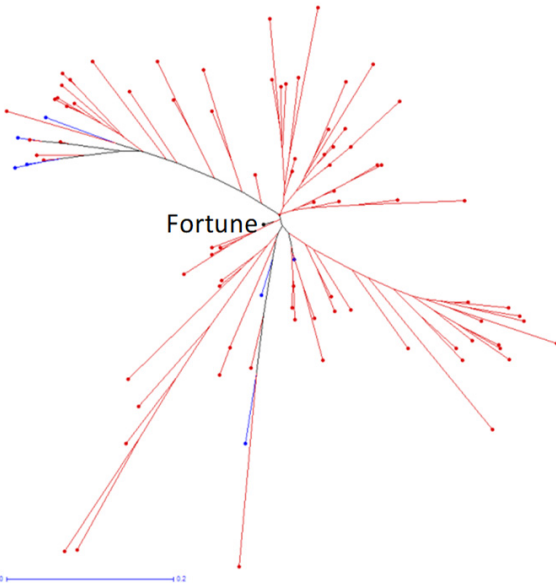

(a)

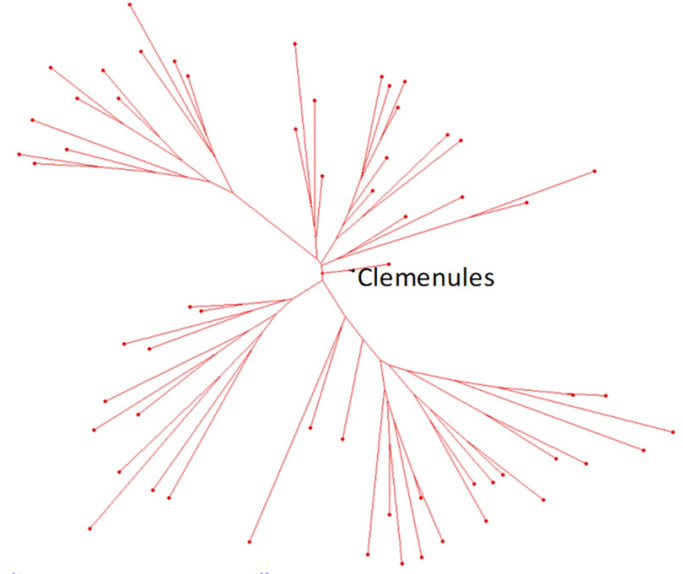

(b)

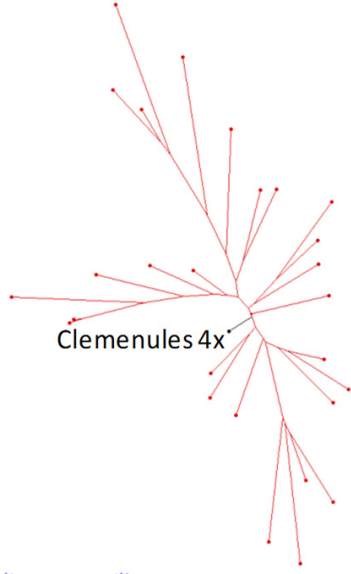

(c)

Figure 5. (a) Neighbor-joining tree obtained from the allelic data of the diploid hybrid population recovered from the self-pollination of the 'Fortune' mandarin by temperature stress (blue) and bud pollination (red). (b) Neighbor-joining tree obtained from the allelic data of the diploid hybrid population recovered from the self-pollination of the 'Clemenules' clementine by bud pollination. (c) Neighbor-joining tree obtained from the allelic data of the tetraploid hybrids population recovered from the self-pollination of the tetraploid 'Clemenules' clementine. The scale for genetic distances over edge is indicated by the blue line length; 0.2 for $(\mathbf{a}, \mathbf{b})$, and 0.1 for (c).

Table 2. Analysis of Mendelian allelic segregation (Chi-squared test with Bonferroni correction for multiple testing) of the recovered plants from the self-pollinated buds of the 'Fortune' mandarin.

\begin{tabular}{cccccc}
\hline Marker & aa & AA & Aa & Chi-Squared & $p$-Value \\
\hline SOS1-M50 & 18 & 26 & 36 & 1.455 & 0.228 \\
mCrCIR05A05 & 17 & 16 & 47 & 0.030 & 0.862 \\
JK-TAA41 & 16 & 18 & 43 & 0.118 & 0.732 \\
PKF-M186 & 22 & 21 & 37 & 0.023 & 0.879 \\
mCrCIR06B07 & 17 & 17 & 43 & 0.000 & 1.000 \\
Ci07C07 & 17 & 15 & 48 & 0.125 & 0.724 \\
NADK2-M285 & 31 & 9 & 40 & 12.100 & 0.001 \\
LAPX-M238 & 17 & 26 & 36 & 1.884 & 0.170 \\
MDH-MP69 & 18 & 24 & 33 & 0.857 & 0.355 \\
FLS-M400 & 18 & 14 & 48 & 0.500 & 0.480 \\
HYB-M62 & 10 & 17 & 53 & 1.815 & 0.178 \\
\hline
\end{tabular}

Detailed information on the markers is provided in Supplementary Table S5. The data under aa, AA and Aa columns indicate the number of individuals with that allelic configuration.

The plants recovered from the bud self-pollination of 'Clemenules' clementine (Experiment 2) were also analyzed with nine SNP markers heterozygous for 'Clemenules' clementine (Supplementary Table S5). By way of example, Figure $4 \mathrm{~b}$ shows the results obtained for the CiC5796-12 SNP marker by identifying three clusters, of which two correspond to the homozygous allelic configurations (AA and CC) and one to heterozygosity. None of these plants were identical to the diploid 'Clemenules' clementine (Figure 5b) as they displayed different allelic configurations (Supplementary Table S8). Potential distortions from Mendelian allelic segregations were tested in the population obtained from the bud pollination for each marker by the Chi-squared test ( 0.05 probability threshold) with Bonferroni correction for multiple testing (Table 3). The genetic analysis agreed with the 
self-pollination hypothesis, as all the diploid hybrids displayed unambiguous alleles of 'Clemenules' clementine in a Mendelian segregation manner. According to the observed segregation, the flow cytometry and histological data, we conclude that the diploid zygotic plants were produced from the self-pollination of 'Clemenules' clementine.

Table 3. Analysis of Mendelian allelic segregation (Chi-squared test with Bonferroni correction for multiple testing) of the recovered plants from the self-pollinated buds of the 'Clemenules' clementine.

\begin{tabular}{cccccc}
\hline Marker & aa & AA & Aa & Chi-Squared & $p$-Value \\
\hline CiC2110-01 & 15 & 16 & 30 & 0.032 & 0.857 \\
CiC5950-02 & 11 & 21 & 29 & 3.125 & 0.077 \\
CiC6278-01 & 10 & 17 & 32 & 1.815 & 0.178 \\
CiC3712-01 & 13 & 21 & 27 & 1.882 & 0.170 \\
JK-TAA41 & 22 & 28 & 14 & 1.778 & 0.182 \\
mCrCIR06B07 & 14 & 31 & 19 & 0.758 & 0.384 \\
CiC5796-12 & 16 & 11 & 34 & 0.926 & 0.336 \\
CiC1380-05 & 18 & 11 & 32 & 1.690 & 0.194 \\
Ci07C07 & 14 & 30 & 20 & 1.059 & 0.303 \\
CiC5164-03 & 17 & 14 & 29 & 0.290 & 0.590 \\
CiC1749-05 & 15 & 12 & 34 & 0.333 & 0.564 \\
CiC5087-01 & 13 & 18 & 30 & 0.806 & 0.369 \\
\hline
\end{tabular}

Detailed information on the markers is provided in Supplementary Table S5. The data under the aa, AA and Aa columns indicate the number of individuals with that allelic configuration.

Allele dosage of the tetraploid plants obtained from the self-pollination of the tetraploid 'Clemenules' clementine (Experiment 3) was verified based on the relative allele signals. For the SSR markers, tetraploid allelic configurations were assigned by the microsatellite allele counting-peak ratios method (MAC-PR; [82]). For the SNP markers, KASPar technology is an efficient way to estimate allele dosage in citrus tetraploid plants $[83,84]$ (Figure 4c). All the obtained tetraploid plants differed from the tetraploid 'Clemenules' clementine (Figure $5 \mathrm{c}$ ) due to the distinct allelic configuration and the several allele doses $(0 / 4 ; 3 / 1 ; 1 / 3$ or $4 / 0)$ for the heterozygous SNPs markers in clementine (the $2 / 2$ dose in the tetraploid) (Supplementary Table S9).

Allelic segregation distortion was tested under random tetrasomic segregation [85] for each marker by the Chi-squared test ( 0.05 probability threshold) with Bonferroni correction for multiple testing. Three SNPs showed significant segregation distortion: CiC5796-12 $(p$-value $=0.030)$; CiC1380-05 $(p$-value $=0.024)$ and CiC1749-05 $(p$-value $=0)($ Table 4$)$. From the histological, flow cytometry and marker results, we conclude that the self-pollination of tetraploid 'Clemenules' clementine surpassed the SI reaction and was able to produce tetraploid zygotic plants.

Table 4. Analysis of tetrasomic random allelic segregation of the tetraploid recovered plants from the self-pollinated flowers of the tetraploid 'Clemenules' clementine.

\begin{tabular}{cccccccc}
\hline Marker & aaaa & aaaA & AAaa & AAAa & AAAA & Chi-Squared & $p$-Value \\
\hline CiC2110-01 & 0 & 7 & 11 & 9 & 2 & 4.483 & 0.345 \\
CiC5950-02 & 2 & 5 & 16 & 3 & 0 & 5.115 & 0.276 \\
CiC6278-01 & 1 & 3 & 12 & 9 & 1 & 3.423 & 0.490 \\
CiC3712-01 & 0 & 7 & 11 & 8 & 3 & 8.052 & 0.090 \\
JK-TAA41 & 1 & 5 & 16 & 3 & 1 & 2.346 & 0.672 \\
mCrCIR06B07 & 1 & 5 & 13 & 5 & 2 & 2.577 & 0.631 \\
CiC5796-12 & 2 & 7 & 7 & 11 & 2 & 10.690 & 0.030 \\
CiC1380-05 & 3 & 10 & 13 & 2 & 1 & 1.207 & 0.024 \\
Ci07C07 & 1 & 4 & 17 & 5 & 1 & 1.804 & 0.772 \\
CiC5164-03 & 0 & 5 & 10 & 9 & 1 & 68.603 & 0.475 \\
CiC1749-05 & 8 & 7 & 12 & 2 & 0 & 5.138 & 0.000 \\
CiC5087-01 & 0 & 2 & 18 & 8 & 1 & 0.273
\end{tabular}

Detailed information on the markers is provided in Supplementary Table S5. The data under the aaaa, aaaA, AAaa, AAAa and AAAA columns indicate the number of individuals with that allelic configuration. 


\section{Discussion}

SI is a relevant trait in citrus because, when coupled with parthenocarpy, it enables seedless fruit production. However, SI can be an obstacle for genetic studies and plant breeding programs. Our results show that the breakdown of SI in citrus can be caused by temperature stress, bud pollination and polyploidization. All the plants obtained by means of temperature stress and bud pollination were diploids, whereas the self-pollination of the tetraploid 'Clemenules' clementine produced, as expected, tetraploid plants. Unfortunately, no 'Clemenules' clementine trees cultivated in containers were available to be cultivated inside growth chambers at $10^{\circ} \mathrm{C}$ and $30^{\circ} \mathrm{C}$. As a result, the comparison in terms of effectiveness between temperature stress (Experiment 1) and polyploidization (Experiment 3) was not possible. However, according to our results, bud pollination (Experiment 2) appears to be a more effective way to break down SI than temperature stress in the 'Fortune' mandarin (Experiment 1) as well as more effective than polyploidization in the 'Clemenules' clementine (Experiment 3).

In Experiment 1, histological observations showed SI breakdown in the 'Fortune' mandarin when the progamic phase took place at a constant temperature of $10^{\circ} \mathrm{C}$. However, very few pollen tubes reached the ovaries in $80 \%$ of the self-pollinated flowers, and no pollen tubes were observed reaching ovaries in $20 \%$ of the self-pollinated flowers, which could indicate that the SI reaction breakdown at $10{ }^{\circ} \mathrm{C}$ is unstable and partial. Distefano et al. [63] suggested that low temperatures delay pistil maturation, and immature tissues allow pollen tube growth until the ovaries. This hypothesis agrees with the results obtained in our work. Recently, Aloisi et al. [65] indicated that temperature contributed to a different activation of the SI reaction in C. clementina, which occurred at an optimal temperature of $25{ }^{\circ} \mathrm{C}$ and was by-passed at $15^{\circ} \mathrm{C}$. For the first time in citrus, we recovered zygotic plants that resulted from self-pollination at $10^{\circ} \mathrm{C}$ of a self-incompatible genotype.

Although we observed very few pollen tubes reaching the basal pistil sections in 2 of the 10 self-pollinated flowers of 'Fortune' mandarin at high temperatures $\left(30{ }^{\circ} \mathrm{C}\right)$, we did not recover fruit, and consequently, seed presence could not be assessed. In a previous research work about the influence of high temperatures on the SI reaction in citrus, Kawano et al. [86] reported that pollen tubes reached the base of styles in self-pollinated flowers at $30^{\circ} \mathrm{C}$ in a self-incompatible 'Hyuganatsu' Japanese variety. In contrast, Distefano et al. $[62,63]$ indicated that constant temperatures at $30{ }^{\circ} \mathrm{C}$ did not affect the SI reaction in clementines. These discrepant results may suggest that the SI reaction breakdown in citrus is genotype-dependent. Nevertheless, more research is needed to shed some light on molecular mechanisms. Yamamoto et al. [60] indicated that alterations in the plasma membrane localization of S-locus receptor kinase genes are responsible for SI breakdown at high temperature in Arabidopsis thaliana. What is clear is that temperature plays a very important role in the SI reaction breakdown in citrus, which could have implications for gametophytic selection (reviewed by Hedhly et al. [87]).

SI breakdown by bud self-pollination is probably related to the fact that SI machinery has not yet been synthesized [88]. This has been known in Petunia since 1934 [89]. Based on histological observations, Distefano et al. [50] reported the SI breakdown by bud pollination in 'Fortune' mandarin, whereas Wakana et al. [66] reported it in clementine based on seeded fruit production from bud self-pollinations. Our results consistently confirmed these previous studies because they are based on histological observations, seed production, and also on demonstrating the zygotic origin by selfing of the recovered plants with the SSR and SNP markers, which had not yet been demonstrated in citrus.

Despite the global agreement of our results with the above-mentioned research, we encountered some differences in the bud developmental stage when SI was surpassed. Distefano et al. [50] reported 11 pollen tubes reaching the style base in 100\% of self-pollinated buds of 'Fortune' mandarin 1 day before anthesis. However, we observed very few pollen tubes $(<5)$ reaching the ovaries in $60 \%$ of self-pollinated buds 1 to 2 days before anthesis (12.5 mm average length), and no pollen tubes were observed in the remaining 40\%. With clementine, Wakana et al. [66] obtained an average of 20.5 seeds in the fruit from the buds 
pollinated between 6 and $8 \mathrm{~mm}$ in length, which suggests that a half-sized flower bud is the optimum stage to produce self-fertilized seeds, and the SI reaction grew beyond this size. This suggestion is supported by our results, although we obtained seedy fruit from self-pollinated buds ( $9.4 \mathrm{~mm}$ average length), which were $60 \%$ of the size compared to those upon anthesis, and the number of seeds per fruit was almost the same as those produced from cross-pollination under field conditions.

Inducing self-compatibility in self-incompatible genotypes can result from either physiological or genetic changes [12,22]. Physiological changes may change over time and can induce different responses to the SI reaction in some genotypes. For example, in a previous work [46], we classified 'Imperial' mandarin and 'Ellendale' tangor as non-strict self-incompatible genotypes because they produced both seedless and low-seeded fruit from self-pollinated flowers, which suggests an impact of environmental conditions [90]. Similarly, Claessen et al. [12] indicated in pear and apple that the strength of the SI reaction differed depending on distinct intrinsic and extrinsic factors, including flower age and quality, temperature and application of plant hormones.

Chromosome doubling is one of the genetic changes that can result in self-compatibility for self-incompatible diploid genotypes [12,22]. This ploidy effect has been studied since the beginning of the last century. Diploid plants are usually associated with SI, whereas their derived tetraploid plants are usually self-compatible [91]. By considering the gametophytic self-incompatibility and tetraploid plants recovered from self-incompatible diploid plants (S1S2) by either chemical treatments or spontaneous chromosome duplication, the genetic configuration for the S locus would be S1S1S2S2, thus producing diploid pollen with either two identical $S$ alleles or two different $S$ alleles. It has been proposed in the Petunia [91], Pyrus [92] and Malus genera [93] that pollen tube growth stops when pollen grain is homozygous for one S allele (S1S1 or S2S2), whereas heteroallelic (S1S2) pollen can grow through the pistil. For instance, the tetraploid progeny recovered from a self-pollinated autotetraploid plant is expected to be self-compatible and heterozygous at the $S$ locus with the following genetic configuration: S1S1S1S2, S1S1S2S2 or S1S2S2S2.

In citrus, information about this phenomenon is scarce, as there is only one previous research work. Yamashita et al. [68] reported SI reaction loss in the tetraploid 'Hyuganatsu' genotype (recovered by spontaneous limb mutation) and obtained $1.14 \pm 1$ well-developed seeds per fruit from selfing. In our work, we obtained the same results using a tetraploid plant of the 'Clemenules' clementine obtained by in vitro shoot-tip grafting combined with colchicine treatment [69]. Self-pollination of tetraploid flowers in anthesis allowed us to recover 29 tetraploid plants, and we demonstrated their zygotic origin with the SSR and SNP markers. This is the first report in citrus for which this phenomenon is formally demonstrated. According to Kim et al. [48], clementines contain S3S11 SI alleles and, in line with the above-indicated hypothesis, only heteroallelic pollen grains can grow through the pistil to fertilize ovules producing heterozygous tetraploid hybrids. This hypothesis should be tested in larger tetraploid progenies obtained by selfing and by the analysis of molecular marker segregation, taking advantage of the SNP markers recently identified in the close vicinity of the citrus $S$ locus located at the beginning of chromosome 7 of the clementine reference genome [27]. As part of our breeding program [45], tetraploid plants of the self-incompatible genotypes 'Chandler' pummelo and 'Moncada' mandarin have been obtained using the same above-described colchicine treatment. The self-pollination of the tetraploid flowers of these genotypes at anthesis allowed us to recover seeds and tetraploid hybrids originated from selfing (data nor shown). This result may indicate that this phenomenon does not depend on the genotype and could be an intrinsic characteristic of citrus reproductive biology or even of the gametophytic self-incompatible system in doubled diploids of self-incompatible diploid genotypes.

Marker segregation distortion is a natural phenomenon [94]. In the genetic analysis of tetraploid plants obtained from self-pollination of the tetraploid 'Clemenules' clementine, we observed segregation distortion in three SNPs markers: CiC1380-05, CiC5796-12 and CiC1749-05. Ollitrault et al. [73] established the reference clementine genetic map and re- 
ported segregation distortion in CiC1380-05 SNP marker in the male and female clementine maps. However, no segregation distortion was observed for CiC5796-12 and CiC1749-05 SNP markers [73]. Regarding these two markers, the segregation distortion observed in our analysis may be associated with the vicinity of genes involved in reproductive biology. CiC5796-12 (LG3, position 41,554,598) is located near the Ciclev10023991m.g gene (LG3; position $42,587,792$ to $42,588,197)$, which is involved with the plant self-incompatibility protein S1. CiC1749-05 (LG8; position 24,429,013) is close to the Ciclev10030173m.g gene (LG8; position 24,433,990 to 24,437,012), which is associated with aberrant pollen development protein, according to the C. clementina v1.0 reference genome, available at Phytozome platform [95]. In the genetic analysis of plants obtained from bud self-pollination of 'Fortune' mandarin, we observed segregation distortion in the NADK2-M285 SNP marker (LG5; position 37,772,763). This marker was not included in the reference clementine map. However, the segregation distortion observed in our study might be explained by the high segregation distortion in most parts of the LG5 reported by Ollitrault et al. [73].

\section{Conclusions}

We analyzed the influence of three potential approaches to induce the breakdown of the SI system in mandarins and clementines: temperature stress, bud pollination and chromosome doubling. The SI phenotype was characterized by a histological study of pollen tube growth and ovule fertilization. The ploidy of the plants obtained in the selfing experiments was characterized by flow cytometry, and their genotyping was performed with SNP and SSR markers. This molecular marker analysis allowed us to demonstrate that all the obtained plants were zygotic from selfing. The three methods were successful in recovering selfed plants, and bud pollination was the most efficient approach. Chromosome doubling was also efficient, but involved developing tetraploid plants, which is only interesting within the framework of triploid variety or in tetraploid rootstock breeding programs. Cold temperature stress allowed us to obtain a few diploid selfed plants. However, this method proved much more complex to apply than bud pollination in specific breeding programs. The recent new insight into the molecular determinants of SI in citrus and our current results would allow the efficiency of producing selfing progenies from self-incompatible genotypes. Furthermore, it would also enable their use for genetic studies and breeding programs.

Supplementary Materials: The following supporting information can be downloaded at: https:/ / www.mdpi.com/article/10.3390/agriculture12020273/s1, Table S1: Pollen tube (PT) growth observed in each self-pollinated flower of the 'Fortune' mandarin at anthesis in the constant temperature regimes of $10^{\circ} \mathrm{C}$ and $30^{\circ} \mathrm{C}$ evaluated in Experiment 1, Table S2: Pollen tube (PT) growth observed in each self-pollinated flower bud of the 'Fortune' mandarin at field conditions in the different flower bud lengths evaluated in Experiment 2, Table S3: Pollen tube (PT) growth observed in each self-pollinated flower bud of the 'Clemenules' clementine at field conditions in the different flower bud lengths evaluated in Experiment 2, Table S4: Pollen tube (PT) growth observed in each self-pollinated flower at anthesis of the tetraploid 'Clemenules' clementine cultivated under field conditions evaluated in Experiment 3, Table S5: Molecular markers used in the genetic analysis with their location, noted alleles and bibliographic reference, Table S6: Genotyping of 7 recovered plants obtained from self-pollination of 'Fortune' mandarin under temperature stress $\left(10^{\circ} \mathrm{C}\right)$ with SSR and SNP markers, Table S7: Genotyping of 81 recovered plants obtained from self-pollination of 'Fortune' mandarin by bud pollination with SSR and SNP markers, Table S8: Genotyping of 61 recovered plants obtained from self-pollination of 'Clemenules' clementine by bud pollination with SSR and SNP markers, Table S9: Genotyping of 29 tetraploid recovered plants obtained from self-pollination of tetraploid 'Clemenules' clementine with SSR and SNP markers.

Author Contributions: Conceptualization, R.M. and P.A.; methodology, R.M.; validation, R.M., P.A. and P.O.; genetic analysis, L.P.; investigation, R.M.; data curation, P.A.; writing—original draft preparation, R.M.; writing-review and editing, P.A., M.C.V., L.N. and P.O.; supervision, P.A.; project administration, P.A.; funding acquisition, M.C.V. All authors have read and agreed to the published version of the manuscript. 
Funding: This research was funded by Project RTA2015-00069-00-00 from the Spanish Ministry of "Economía y Competividad" and Fondo Europeo de Desarrollo Regional (FEDER).

Institutional Review Board Statement: Not applicable.

Informed Consent Statement: Not applicable.

Data Availability Statement: The data presented in this study are available in the article or as Supplementary Materials.

Conflicts of Interest: The authors declare no conflict of interest. The funders had no role in the design of the study; in the collection, analyses, or interpretation of data; in the writing of the manuscript, or in the decision to publish the results.

\section{References}

1. Franklin-Tong, V.E. Self-Incompatibility in Flowering Plants: Evolution, Diversity, and Mechanisms; Franklin-Tong, V.E., Ed.; Springer: Berlin/Heidelberg, Germany, 2008; ISBN 978-3-540-68485-5.

2. Allen, A.M.; Hiscock, S.J. Evolution and phylogeny of self-incompatibility systems in angiosperms. In Self-Incompatibility in Flowering Plants: Evolution, Diversity, and Mechanisms; Franklin-Tong, V.E., Ed.; Springer: Berlin/Heidelberg, Germany, 2008; pp. 73-101, ISBN 978-3-540-68486-2.

3. Barrett, S.C.H. The evolution of plant reproductive systems: How often are transitions irreversible? Proc. R. Soc. B Biol. Sci. 2013, 280, 20130913. [CrossRef]

4. Gibbs, P.E. Late-acting self-incompatibility-The pariah breeding system in flowering plants. New Phytol. 2014, 203, 717-734. [CrossRef]

5. Raduski, A.R.; Haney, E.B.; Igić, B. The expression of self-incompatibility in angiosperms is bimodal. Evolution 2011, 66, 1275-1283 [CrossRef] [PubMed]

6. Charlesworth, D.; Vekemans, X.; Castric, V.; Glémin, S. Plant self-incompatibility systems: A molecular evolutionary perspective. New Phytol. 2005, 168, 61-69. [CrossRef]

7. Takayama, S.; Isogai, A. Self-incompatibility in plants. Annu. Rev. Plant Biol. 2005, 56, 467-489. [CrossRef]

8. McClure, B. S-RNase and SLF determine S-haplotype-specific pollen recognition and rejection. Plant Cell 2004, 16, 2840-2847. [CrossRef] [PubMed]

9. Yamamoto, M.; Nishio, T. Commonalities and differences between Brassica and Arabidopsis self-incompatibility. Hortic. Res. 2014, 1, 14054. [CrossRef]

10. Sehgal, N.; Singh, S. Progress on deciphering the molecular aspects of cell-to-cell communication in Brassica self-incompatibility response. 3 Biotech 2018, 8, 347. [CrossRef] [PubMed]

11. Maliepaard, C.; Alston, F.H.; Van Arkel, G.; Brown, L.M.; Chevreau, E.; Dunemann, F.; Evans, K.M.; Gardiner, S.; Guilford, P.; Van Heusden, A.W. Aligning male and female linkage maps of apple (Malus pumila Mill.) using multi-allelic markers. Theor. Appl. Genet. 1998, 97, 60-73. [CrossRef]

12. Claessen, H.; Keulemans, W.; Van de Poel, B.; De Storme, N. Finding a compatible partner: Self-incompatibility in european pear (Pyrus communis); molecular control, genetic determination, and impact on fertilization and fruit set. Front. Plant Sci. 2019, 10, 407. [CrossRef] [PubMed]

13. Abdallah, D.; Baraket, G.; Perez, V.; Ben Mustapha, S.; Salhi-Hannachi, A.; Hormaza, J.I. Analysis of self-incompatibility and genetic diversity in diploid and hexaploid plum genotypes. Front. Plant Sci. 2019, 10, 896. [CrossRef]

14. Brancher, T.L.; Hawerroth, M.C.; Kvitschal, M.V.; Manenti, D.C.; Guidolin, A.F. Self-incompatibility alleles in important genotypes for apple breeding in Brazil. Crop Breed. Appl. Biotechnol. 2020, 20, e28652041. [CrossRef]

15. Knight, R.; Rogers, H.H. Sterility in Theobroma cacao L. Nature 1953, 172, 164. [CrossRef]

16. Alagna, F.; Caceres, M.E.; Pandolfi, S.; Collani, S.; Mousavi, S.; Mariotti, R.; Cultrera, N.G.M.; Baldoni, L.; Barcaccia, G. The paradox of self-fertile varieties in the context of self-incompatible genotypes in olive. Front. Plant Sci. 2019, 10, 725. [CrossRef]

17. Zhang, S.; Liang, M.; Wang, N.; Xu, Q.; Deng, X.; Chai, L. Reproduction in woody perennial citrus: An update on nucellar embryony and self-incompatibility. Plant Reprod. 2018, 31, 43-57. [CrossRef]

18. Goldberg, E.E.; Kohn, J.R.; Lande, R.; Robertson, K.A.; Smith, S.A.; Igić, B. Species selection maintains self-incompatibility. Science 2010, 330, 493-495. [CrossRef]

19. Surridge, C. Self-incompatibility: Avoiding inbreeding in Arabidopsis. Nat. Plants 2015, 1, 15198. [CrossRef]

20. Lin, Z.; Eaves, D.J.; Sanchez-Moran, E.; Franklin, F.C.; Franklin-Tong, V.E. The Papaver rhoeas S determinants confer selfincompatibility to Arabidopsis thaliana in planta. Science 2015, 350, 684-687. [CrossRef]

21. Abdallah, D.; Baraket, G.; Perez, V.; Salhi Hannachi, A.; Hormaza, J.I. Self-compatibility in peach [Prunus persica (L.) Batsch]: Patterns of diversity surrounding the S-locus and analysis of SFB alleles. Hortic. Res. 2020, 7, 170. [CrossRef]

22. de Nettancourt, D. Incompatibility in angiosperms. Sex. Plant Reprod. 1997, 10, 185-199. [CrossRef]

23. Ferrer, M.M.; Good, S.V. Self-sterility in flowering plants: Preventing self-fertilization increases family diversification rates. Ann. Bot. 2012, 110, 535-553. [CrossRef] [PubMed] 
24. Igic, B.; Bohs, L.; Kohn, J.R. Ancient polymorphism reveals unidirectional breeding system shifts. Proc. Natl. Acad. Sci. USA 2006, 103, 1359-1363. [CrossRef] [PubMed]

25. Sawada, H.; Morita, M.; Iwano, M. Self/non-self recognition mechanisms in sexual reproduction: New insight into the selfincompatibility system shared by flowering plants and hermaphroditic animals. Biochem. Biophys. Res. Commun. 2014, 450, 1142-1148. [CrossRef] [PubMed]

26. Tovar-Mendez, A.; McClure, B. Plant reproduction: Self-incompatibility to go. Curr. Biol. 2016, 26, R115-R117. [CrossRef] [PubMed]

27. Ollitrault, P.; Ahmed, D.; Costantino, G.; Evrard, J.C.; Cardi, C.; Mournet, P.; Perdereau, A.; Froelicher, Y. Segregation distortion for male parents in high density genetic maps from reciprocal crosses between two self-incompatible cultivars confirms a gametophytic system for self-incompatibility in citrus. Agriculture 2021, 11, 379. [CrossRef]

28. Vilanova, S.; Badenes, M.L.; Burgos, L.; Martínez-Calvo, J.; Llácer, G.; Romero, C. Self-compatibility of two apricot selections is associated with two pollen-part mutations of different nature. Plant Physiol. 2006, 142, 629-641. [CrossRef]

29. Soost, R.K. Incompatibility alleles in genus citrus. Proc. Am. Soc. Hort. Sci. 1965, 87, 176-180.

30. Soost, R.K. The incompatibility gene system. Proc. Int. Soc. Citric. 1969, 1, 189-190.

31. Vardi, A.; Neumann, H.; Frydman-Shani, A.; Yaniv, Y.; Spiegel-Roy, P. Tentative model on the inheritance of juvenility, selfincompatibility and parthenocarpy. Acta Hortic. 2000, 535, 199-206. [CrossRef]

32. Caruso, M.; Merelo, P.; Distefano, G.; La Malfa, S.; Lo Piero, A.R.; Tadeo, F.R.; Talon, M.; Gentile, A. Comparative transcriptome analysis of stylar canal cells identifies novel candidate genes implicated in the self-incompatibility response of Citrus clementina. BMC Plant Biol. 2012, 12, 20. [CrossRef]

33. Honsho, C.; Ushijima, K.; Anraku, M.; Ishimura, S.; Yu, Q.; Gmitter, F.G.; Tetsumura, T. Association of T2/S-RNase with self-incompatibility of japanese citrus accessions examined by transcriptomic, phylogenetic, and genetic approaches. Front. Plant Sci. 2021, 12, 638321. [CrossRef] [PubMed]

34. Liang, M.; Cao, Z.; Zhu, A.; Liu, Y.; Tao, M.; Yang, H.; Xu, Q.; Wang, S.; Liu, J.; Li, Y.; et al. Evolution of self-compatibility by a mutant Sm -RNase in citrus. Nat. Plants 2020, 6, 131-142. [CrossRef]

35. Wilms, H.J.; Van Went, J.L.; Cresti, M.; Ciampolini, F. Structural aspects of female sterility in Citrus limon. Acta Bot. Neerl. 1983, 32, 87-96. [CrossRef]

36. Osawa, I. Cytological and experimental studies in Citrus. J. Coll. Agric. Tokyo Univ. 1912, 4, 83-116.

37. Wong, C.Y. The influence of pollination on seed development in certain varieties of citrus. Soc. Hortic. Sci. 1939, 37, 161-164.

38. Yamasaki, A.; Kitajima, A.; Ohara, N.; Tanaka, M.; Hasegawa, K. Characteristics of arrested seeds in Mukaku kishu-type seedless citrus. J. Jpn. Soc. Hortic. Sci. 2009, 78, 61-67. [CrossRef]

39. Yamasaki, A.; Kitajima, A.; Ohara, N.; Tanaka, M.; Hasegawa, K. Histological study of expression of seedlessness in Citrus kinokuni 'Mukaku Kishu' and its progenies. J. Am. Soc. Hortic. Sci. 2007, 132, 869-875. [CrossRef]

40. Goto, S.; Yoshioka, T.; Ohta, S.; Kita, M.; Hamada, H.; Shimizu, T. Segregation and heritability of male sterility in populations derived from progeny of satsuma mandarin. PLoS ONE 2016, 11, e0162408. [CrossRef]

41. Goldenberg, L.; Yaniv, Y.; Porat, R.; Carmi, N. Effects of gamma-irradiation mutagenesis for induction of seedlessness, on the quality of mandarin fruit. Food Nutr. Sci. 2014, 5, 943-952. [CrossRef]

42. Bermejo, A.; Pardo, J.; Cano, A. Influence of gamma irradiation on seedless citrus production: Pollen germination and fruit quality. Food Nutr. Sci. 2011, 2, 169-180. [CrossRef]

43. Ollitrault, P.; Froelicher, Y.; Dambier, D.; Luro, F.; Yamamoto, M. Seedlessness and ploidy manipulation. In Citrus Genetics, Breeding and Biotechnology; Khan, I., Ed.; CABI: Wallingfor, UK, 2007; pp. 197-218. ISBN 9780851990194.

44. Ollitrault, P.; Dambier, D.; Francois, L.; Froelicher, Y. Ploidy manipulation for breeding seedless triploid citrus. In Plant Breeding Reviews; Janick, J., Ed.; John Wiley \& Sons, Inc.: Hoboken, NJ, USA, 2007; Volume 30, pp. 323-352. ISBN 9780470380130.

45. Navarro, L.; Aleza, P.; Cuenca, J.; Juárez, J.; Pina, J.A.; Ortega, C.; Navarro, A.; Ortega, V. The mandarin triploid breeding program in Spain. Acta Hortic. 2015, 1065, 389-396. [CrossRef]

46. Montalt, R.; Vives, M.C.; Navarro, L.; Ollitrault, P.; Aleza, P. Parthenocarpy and self-incompatibility in mandarins. Agronomy 2021, 11, 2023. [CrossRef]

47. Yamamoto, M.; Kubo, T.; Tominaga, S. Self- and cross-incompatibility of various citrus accessions. J. Jpn. Soc. Hortic. Sci. 2006, 75, 372-378. [CrossRef]

48. Kim, J.-H.; Handayani, E.; Wakana, A.; Sato, M.; Miyamoto, M.; Miyazaki, R.; Zhou, X.; Sakai, K.; Mizunoe, Y.; Shigyo, M.; et al. Distribution and evolution of Citrus accessions with S3 and/or S11 alleles for self-incompatibility with an emphasis on sweet orange [Citrus sinensis (L.) Osbeck; SfS3 or SfS3sm]. Genet. Resour. Crop Evol. 2020, 67, 2101-2117. [CrossRef]

49. Ngo, B.X.; Wakana, A.; Park, S.M.; Nada, Y.; Fukudome, I. Pollen tube behaviors in self-incompatible and self-compatible citrus cultivars. J. Fac. Agric. Kyushu Univ. 2001, 45, 443-457. [CrossRef]

50. Distefano, G.; Las Casas, G.; La Malfa, S.; Gentile, A.; Tribulato, E.; Herrero, M. Pollen tube behavior in different mandarin hybrids. J. Am. Soc. Hortic. Sci. 2009, 134, 583-588. [CrossRef]

51. Distefano, G.; Caruso, M.; la Malfa, S.; Gentile, A.; Tribulato, E. Histological and molecular analysis of pollen-pistil interaction in clementine. Plant Cell Rep. 2009, 28, 1439-1451. [CrossRef]

52. Eti, S.; Stosser, R. Pollen tube growth and development of ovules in relation to fruit set in mandarines, cv.'Clementine' $(\mathrm{Citrus}$ reticulata Blanco). Acta Hortic. 1992, 621-625. [CrossRef] 
53. East, E.M. Genetical aspects of self- and cross-sterility. Am. J. Bot. 1923, 10, 468-473. [CrossRef]

54. Herrero, M.; Dickinson, H.G. Ultrastructural and physiological differences between buds and mature flowers of Petunia hybrida prior to and following pollination. Planta 1980, 148, 138-145. [CrossRef]

55. Kim, H.J.; Niimi, Y. Frequency of viable seeds obtained from several Lilium spp. cross-pollinated at different floral stages. J. Jpn. Soc. Hortic. Sci. 2002, 71, 231-235. [CrossRef]

56. Hiscock, S.J.; Dickinson, H.G. Unilateral incompatibility within the brassicaceae: Further evidence for the involvement of the self-incompatibility (S)-locus. Theor. Appl. Genet. 1993, 86, 744-753. [CrossRef] [PubMed]

57. Ascher, P.D.; Peloquin, S.J. Influence of temperature on incompatible and compatible pollen tube growth in Lilium longiflorum. Can. J. Genet. Cytol. 1966, 8, 661-664. [CrossRef]

58. Campbell, R.J.; Linskens, H.F. Temperature effects on self incompatibility in Lilium longiflorum. Theor. Appl. Genet. 1984, 68, 259-264. [CrossRef] [PubMed]

59. Townsend, C.E. Self-compatibility studies with diploid alsike clover, Trifolium hybridum L. III. Response to temperature. Crop Sci. 1968, 8, 269-272. [CrossRef]

60. Yamamoto, M.; Nishimura, K.; Kitashiba, H.; Sakamoto, W.; Nishio, T. High temperature causes breakdown of S haplotypedependent stigmatic self-incompatibility in self-incompatible Arabidopsis thaliana. J. Exp. Bot. 2019, 70, 5745-5751. [CrossRef]

61. Lewis, D. Competition and dominance of incompatibility alleles in diploid pollen. Heredity 1947, 1, 85-108. [CrossRef]

62. Distefano, G.; Hedhly, A.; Las Casas, G.; La Malfa, S.; Herrero, M.; Gentile, A. Male-female interaction and temperature variation affect pollen performance in citrus. Sci. Hortic. (Amst.) 2012, 140, 1-7. [CrossRef]

63. Distefano, G.; Gentile, A.; Hedhly, A.; La Malfa, S. Temperatures during flower bud development affect pollen germination, self-incompatibility reaction and early fruit development of clementine (Citrus clementina Hort. ex Tan.). Plant Biol. 2018, 20, 191-198. [CrossRef]

64. Montalt, R.; Cuenca, J.; Vives, M.C.; Navarro, L.; Ollitrault, P.; Aleza, P. Influence of temperature on the progamic phase in Citrus. Environ. Exp. Bot. 2019, 166, 103806. [CrossRef]

65. Aloisi, I.; Distefano, G.; Antognoni, F.; Potente, G.; Parrotta, L.; Faleri, C.; Gentile, A.; Bennici, S.; Mareri, L.; Cai, G.; et al Temperature-dependent compatible and incompatible pollen-style interactions in Citrus clementina Hort. ex Tan. show different transglutaminase features and polyamine pattern. Front. Plant Sci. 2020, 11, 1018. [CrossRef] [PubMed]

66. Wakana, A.; Ngo, B.X.; Fukudome, I.; Kajiwara, K. Estimation of the degree of self-incompatibility reaction during flower bud development and production of self-fertilized seeds by bud pollination in self-incompatible Citrus cultivars. J. Fac. Agric. Kyushu Univ. 2004, 49, 307-320. [CrossRef]

67. Aleza, P.; Froelicher, Y.; Schwarz, S.; Agustí, M.; Hernández, M.; Juárez, J.; Luro, F.; Morillon, R.; Navarro, L.; Ollitrault, P. Tetraploidization events by chromosome doubling of nucellar cells are frequent in apomictic citrus and are dependent on genotype and environment. Ann. Bot. 2011, 108, 37-50. [CrossRef] [PubMed]

68. Yamashita, K.; Oda, K.; Nakamura, N. Seed development in self-pollination of 4X Hyuganatsu and reciprocal crosses between $2 \mathrm{X}$ and $4 \mathrm{X}$ Hyuganatsu, and overcoming the self-incompatibility of $2 \mathrm{X}$ Hyuganatsu using pollen of $4 \mathrm{X}$ Hyuganatsu. J. Jpn. Soc. Hortic. Sci. 1990, 59, 23-28. [CrossRef]

69. Aleza, P.; Juárez, J.; Ollitrault, P.; Navarro, L. Production of tetraploid plants of non apomictic citrus genotypes. Plant Cell Rep. 2009, 28, 1837-1846. [CrossRef] [PubMed]

70. Johansen, D. Plant Microtechniques; McGraw-Hill: New York, NY, USA, 1940.

71. Linskens, F.H.; Esser, K. Über eine spezifische anfarbung der pollenschlauche im griffel und die zahl der kallospefropfen nach slbstdung und femddung. Naturwissenschaften 1957, 44, 16. [CrossRef]

72. Adhikari, P.B.; Liu, X.; Kasahara, R.D. Mechanics of pollen tube elongation: A perspective. Front. Plant Sci. $2020,11,589712$. [CrossRef]

73. Ollitrault, P.; Terol, J.; Chen, C.; Federici, C.T.; Lotfy, S.; Hippolyte, I.; Ollitrault, F.; Bérard, A.; Chauveau, A.; Cuenca, J.; et al. A reference genetic map of $\mathrm{C}$. clementina hort. ex Tan.; citrus evolution inferences from comparative mapping. BMC Genom. 2012, 13, 593. [CrossRef]

74. Cuenca, J.; Froelicher, Y.; Aleza, P.; Juárez, J.; Navarro, L.; Ollitrault, P. Multilocus half-tetrad analysis and centromere mapping in citrus: Evidence of SDR mechanism for $2 \mathrm{n}$ megagametophyte production and partial chiasma interference in mandarin $\mathrm{cV}$ "Fortune". Heredity 2011, 107, 462-470. [CrossRef]

75. Kijas, J.M.H.; Thomas, M.R.; Fowler, J.C.S.; Roose, M.L. Integration of trinucleotide microsatellites into a linkage map of Citrus. Theor. Appl. Genet. 1997, 94, 701-706. [CrossRef]

76. Froelicher, Y.; Dambier, D.; Bassene, J.B.; Constantino, G.; Lotfy, S.; Didout, C.; Beaumont, V.; Brottier, P.; Risterucci, A.M.; Luro, F.; et al Characterization of microsatellite markers in mandarin orange (Citrus reticulata Blanco). Mol. Ecol. Resour. 2008, 8, 119-122. [CrossRef] [PubMed]

77. Garcia-Lor, A.; Curk, F.; Snoussi-Trifa, H.; Morillon, R.; Ancillo, G.; Luro, F.; Navarro, L.; Ollitrault, P. A nuclear phylogenetic analysis: SNPs, indels and SSRs deliver new insights into the relationships in the 'true citrus fruit trees' group (Citrinae, Rutaceae) and the origin of cultivated species. Ann. Bot. 2013, 111, 1-19. [CrossRef] [PubMed]

78. Ollitrault, P.; Terol, J.; Garcia-Lor, A.; Bérard, A.; Chauveau, A.; Froelicher, Y.; Belzile, C.; Morillon, R.; Navarro, L.; Brunel, D.; et al. SNP mining in C. clementina BAC end sequences; transferability in the Citrus genus (Rutaceae), phylogenetic inferences and perspectives for genetic mapping. BMC Genom. 2012, 13, 13. [CrossRef] 
79. Cuppen, E. Genotyping by allele-specific amplification (KASPar). CSH Protoc. 2007, 2007, pdb.prot4841. [CrossRef]

80. Perrier, X.; Jacquemoud-Collet, J.P. DARwin Software. Available online: http:/ / darwin.cirad.fr/2006 (accessed on 28 December 2021).

81. Saitou, N.; Nei, M. The neighbor-joining method: A new method for reconstructing phylogenetic trees. Mol. Biol. Evol. 1987, 4, 406-425. [CrossRef]

82. Esselink, G.D.; Nybom, H.; Vosman, B. Assignment of allelic configuration in polyploids using the MAC-PR (microsatellite DNA allele counting-Peak ratios) method. Theor. Appl. Genet. 2004, 109, 402-408. [CrossRef] [PubMed]

83. Cuenca, J.; Aleza, P.; Navarro, L.; Ollitrault, P. Assignment of SNP allelic configuration in polyploids using competitive allelespecific PCR: Application to citrus triploid progeny. Ann. Bot. 2013, 111, 731-742. [CrossRef]

84. Aleza, P.; Cuenca, J.; Juárez, J.; Ollitrault, P.; Navarro, L. Differences in the genetic structure of citrus triploid hybrids recovered from 2x x 2x and 4x x 2x sexual hybridizations. Acta Hortic. 2015, 1065, 487-493. [CrossRef]

85. Muller, H.J. A new mode of segregation in Gregory's tetraploid primulas. Am. Nat. 1914, 48, 508-512. [CrossRef]

86. Kawano, S.; Li, Y.; Yahata, M.; Kunitake, H. Effect of temperature on self-incompatibility in Citrus pistil and mature pollen culture systems. Acta Hortic. 2016, 1135, 117-122. [CrossRef]

87. Hedhly, A.; Hormaza, J.I.; Herrero, M. Global warming and sexual plant reproduction. Trends Plant Sci. 2009, 14, 30-36. [CrossRef] [PubMed]

88. Cabin, R.; Evans, A.; Jennings, D.; Marshall, D.; Mitchell, R.; Sher, A. Using bud pollinations to avoid self-incompatibility: Implications from studies of three mustards. Can. J. Bot. 1996, 74, 285-289. [CrossRef]

89. Yasuda, S. Physiological research on self-incompatibility in Petunia violacea. Bull. Imp. Coll. Agric. For. Marioka Nippon. 1934, 20, 1-82.

90. Sykes, S.R. The effect on Citrus fruit of excluding pollinating insects at flowering and implications for breeding new seedless cultivars. J. Hortic. Sci. Biotechnol. 2008, 83, 713-718. [CrossRef]

91. Golz, J.F.; Clarke, A.E.; Newbigin, E. Mutational approaches to the study of self-incompatibility: Revisiting the pollen-part mutants. Ann. Bot. 2000, 85, 95-103. [CrossRef]

92. Crane, M.B.; Lewis, D. Genetical studies in pears. III Incompatibility and sterility. J. Genet. 1942, 43, 31-43. [CrossRef]

93. Adachi, Y.; Komori, S.; Hoshikawa, Y.; Tanaka, N.; Abe, K.; Bessho, H.; Watanabe, M.; Suzuki, A. Characteristics of fruiting and pollen tube growth of apple autotetraploid cultivars showing self-compatibility. J. Jpn. Soc. Hortic. Sci. 2009, 78, 402-409. [CrossRef]

94. Zuo, J.-F.; Niu, Y.; Cheng, P.; Feng, J.-Y.; Han, S.-F.; Zhang, Y.-H.; Shu, G.; Wang, Y.; Zhang, Y.-M. Effect of marker segregation distortion on high density linkage map construction and QTL mapping in Soybean (Glycine max L.). Heredity 2019, 123, 579-592. [CrossRef]

95. Phytozome 13. Available online: https:/ / phytozome-next.jgi.doe.gov/ (accessed on 28 December 2021). 